\title{
Die Regulationserscheinungen bei Pennaria Cavolinii ${ }^{1}$.
}

\author{
Von
}

Reinhard Gast und Emil Godlewski jun.

Mit Tafel II und III und 22 Figuren im Text.

Eingegangen am 23. Oktober 1902.

\section{Inhaltsübersicht.}

I. Einleitung . . . . . . . . . . . . . . . . . . 76

II. Regulationserscheinungen an größeren Stämmen mit ihren Seitenästen 79

1. Regeneration der Hydranten . . . . . . . . . . . . 83

2. Degeneration der Hydranten . . . . . . . . . . . . . . . 87

3. Verlagerung des Cönosarks. . . . . . . . . . . . . . . . . . 91

4. Spontanes Abtrennen leerer Perisarkröhrchen . . . . . . . . . 96

5. Bildung neuer Sprossen, resp. Stolonen . . . . . . . . . 100

III. Regulationserscheinungen an Stammstücken mit Seitenästen . . . . . 102

IV. Regulationserscheinungen an kleinen Stammstücken ohne Seitenäste . 107

V. Regulationserscheinungen an Hauptstämmen nach Absçheiden aller

Seitenäste . . . . . . . . . . . . . . . . . . . 109

VI. Regenerationserscheinungen an isolirten Seitenästen . . . . . . 110

VII. Ist die Regeneration der Hydranten bei Pennaria vom Licht abhängig? 111

VIII. Resultate der Experimente . . . . . . . . . . . . . . . . . 112

\section{Einleitung.}

Die Erscheinungen, welche nach dem Zerschneiden von PennariaStämmen oder nach Abtragen einzelner Theile derselben hervortreten, können nicht als einfache Regenerationsphänomene bezeichnet werden. Wir heobachten im Laufe der der Operation folgenden Processe das Wiederbilden der abgeschnittenen Theile, wie auch die Degenerationserscheinungen der einzelnen Organe, die Verlagerungen der lebenden

1) Die Arbeit wurde im Sommer 1902 auf der Zoologischen Station in Neapel ausgeführt. 
Elemente, das spontane Abschneiden anderer Organismentheile - Erseheinungen mannigfaltiger Art, die sich schwer unter dem Begriff der Regeneration zusammenfassen lassen. Die Summe dieser Vorgänge bezeichnen wir hier als Regulationserscheinungen im Sinne von DRIESCH ${ }^{1}$.

Der Einfluss der äußeren Faktoren anf die Regenerationsprocesse bei Pennaria ist schon Gegenstand einiger Untersuchungen gewesen.

LOEB hat bei seinen klassischen Experimenten über Heteromorphose den Einfluss des festen Bodens auf den Regenerationsverlauf auch bei Pennaria geprüft. Bei seinen früheren Untersuchungen mit Tubularia hatte er festgestellt, dass unter bestimmten Bedingungen Körpertheile regenerativ entstehen können, die unter normalen Bedingungen nicht entstehen würden. So entsteht bei Tubularia an einem. Stammstiick beiderseits ein Polyp, wenn das Stück frei vom Wasser umspült wird; wenn das Stiuck aber mit dem aboralen Ende mit festem Boden in Berührung steht, so bildet sich an diesem Ende ein Stolo, am oralen ein Polyp. An beiden Enden Stolonen zu erhalten ist indessen bei Tubularia noch nicht gelungen.

Pennaria erwies sich in dieser Beziehung als giinstigeres Objekt. Denn LoEB (1893) hat bewiesen (pag. 41): "In Pennaria I succeeded repeatedly in producing roots at both ends of a small stem that bore no polyps. « Ferner hat er festgestellt, dass die Organe von Pennaria, welche in Kontakt mit festem Boden gebracht werden, immer Stolonen (roots) produciren (wenn das Individuum überhaupt Regenerationsvermögen besitzt); Organe, welche vom Wasser frei umspült werden, produciren immer Hydranten.

Die Angaben von Loeb über den Einfluss vom festen Boden auf die Regeneration bei Pennaria bestätigt Miss Peebles und fügt noch Beobachtungen über den die Regeneration begiunstigenden Einfluss des Lichtes hinzu.

Bevor wir auf unsere Experimente näher eingehen, mögen zum besseren Verständnis der in der vorliegenden Arbeit beschriebenen regulatorischen Vorgänge bei Pennaria Cavolinii einige Notizen über den morphologischen Aufbau dieses Hydroiden vorausgeschickt

1) "Regulation ist ein am lebenden Organismus geschehender Vorgang oder die Änderung eines solchen Vorganges, durch welchen oder durch welche eine irgendwie gesetzte Störnng seines vorher bestandenen ,normalen' Zustandes ganz oder theilweise, direkt oder indirekt kompensirt und so der ,normale' Zustand oder wenigstens eine Annäherung an ihn wieder herbeigefiuhrt wird. (DRIEsch, Organische Regulationen. pag. 92.) 
werden. Auf einer netzförmig verzweigten Hydrorhiza erheben sich die meist schwach gebogenen oft über $30 \mathrm{~cm}$ Länge erreichenden Stämme. An den Stämmen bezeichnen wir als apicales Stammende die freie von der Cotylorhiza abgewendete und von einem Hydranten abgeschlossene Spitze des Stockes, als basales, das in die Cotylorhiza übergehende Stammende, resp. bei Stammstücken die diesen Enden entsprechenden Theile. Zweiseitig und alternirend mit einander entspringen vom Stamm die Seitenäste, stets schräg dem apicalen Stammende zugewendet. Auf diesen Seitenästen stehen in regelmäBigen Abständen auf der dem apicalen Stammende zugewendeten Seite die einzelnen Hydranten; ein Hydrant schließt das freie vom Stamm abgekehrte Ende des Seitenastes, das distale ab; als proximales Ende wird das in den Stamm übergehende Aststïck bezeichnet. Die Länge der Seitenäste nimmt von der Spitze des Stammes basalwärts zu. Da die Hydranten an allen Ästen in gleichen Abständen von einander stehen, tragen die unteren dem'Stammende nächsten Seitenäste (die basalen) die größte Zahl von $\mathrm{Hy}-$ dranten, während deren Zahl an den dem apicalen Stammende näher liegenden Seitenästen (den ap i calen) abnimmt.

Was den histologischen Auf ban betrifft, so besteht der Thierstock aus dem Weichkörper, dem Cönosark, und dem dasselbe einhïllenden Schntz- und Stützorgan, dem Perisark, aus dem nur die einzelnen Hydrantenköpfe frei hervorragen. Das Cönosark besteht aus Ekto- und Entoderm, zwischen denen eine gut entwickelte Basalmembrau die Grenze bildet. Die Ektodermzellen scheiden auf ihrer Oberfläche das aus einzelnen dünnen Schichten zusammengesetzte Perisark aus und liegen unter gewöhnlichen Bedingungen dieser Perisarkröhre dicht an. Die Entodermzellen begrenzen die Cönosarkhöhle. An der breiteren Basis der Hydranten sitzt der einreihige Kranz der langen Basaltentakel, während auf dem Riüssel in zwei oder drei unregelmäßigen Reihen die kurzen an ihrem verdickten knopfförmigen Ende mit Nesselzellen bewehrten Knopf- oder Hypostomtentakel aufsitzen. - Wegen der mannigfaltigen Beziehungen, die zwischen Regeneration und dem unter normalen Bedingungen sich vollziehenden Wachstum bestehen (rgl. MORGAN), mögen hier einige Bemerkungen über dasselbe folgen. Das erste Stadium eines jungen Pennariastockes stellt ein von der Hydrorhiza sich erhebender ungegliederter Stamm dar, dessen freies Ende ein Hydrant bildet. Dicht unterhalb des Endhydranten bildet sich eine neue Knospe; diese entfaltet sich zum Hydranten, der durch kräftiges Wachsthum 
seines Stiels den ersten Seitenast bildet. Zwischen Endhydrant des Stammes und diesem ersten Seitenast findet ein lebhaftes Stammwachsthum statt. Bald bildet sich wieder unterhalb des Endhydranten, aber anf der dem ersten Seitenast entgegengesetzten Seite eine nene Knospe, die Anlage des zweiten Seitenastes. Durch weiteres Wachsthum schieben sich alternirend zwischen dem Endhydranten des Stammes und dem jüngsten Seitenast immer neue Seitenäste ein, so dass die jüngste Astanlage stets dem ältesten Stammbydranten am nächsten steht. An den Seitenästen wiederholt sich dasselbe Wachsthumsbild, nur dass hier die neuen Anlagen stets auf der der Stammspitze zugekehrten, nie auf der anderen Seite entstehen.

In allen Fällen, wo die Beobachtung des lebenden Objektes zur Erkenntnis der sich abspielenden Vorgänge nicht genügte, wurden die Versuchsobjekte fixirt (Sublimat $+5 \%$ Essigsäure), dann in der üblichen Weise in Paraffin überführt und in Serien zerlegt. Als Schnittfärbung gab die besten Bilder Hämalaun-Eosin-Färbung. Ein wichtiges Hilfsmittel für die Untersuchung bildeten auch Totalpräparate nach Vorfärben mit MAYER's Parakarmin und Einschluss in VossLeR's Terpentin direkt aus 95\% igen Alkohol.

\section{Regulationserscheinungen an grölseren Stämmen mit ihren Seitenästen.}

Als Untersuchungsobjekt für die Experimente, die wir zuerst schildern wollen, dienten $20-40 \mathrm{~mm}$ lange Stämme von Pennaria mit sieben bis acht Seitenästen jederseits. Die an dem apicalen Ende und an den Seitenästen sich befindenden Polypen wurden abgeschnitten, ihre Zahl betrug zwischen 50 und 100. Von diesem Versuchsmaterial wurde nach der Operation ein Theil in Glasschalen gebracht und auf den Gefäßboden hingelegt. Bei täglichem Wasserwechsel hielten sich die Stämme mehrere Tage lebenskräftig auch in verhältnismäßig kleinen Schalen. Die anderen Stämme wurden in Bassins mit fließendem Seewasser aufgehängt.

Wir wollen zuerst die Regulationserscheinungen beschreiben, welche an den aufgehängten Stämmen beobachtet wurden, und zwar werden wir zuerst einen Überblick über alle regulativen Vorgänge geben, ohne auf die genaue Analyse der morphologischen Processe einzugehen, welche im nächsten Kapitel folgen soll. Diese allgemeine 
Schilderung der nach der Operation sich abspielenden Vorgänge wird in ihren verschiedenen Stadien durch die Textfiguren $1-6$ veranschanlicht, welche nach unseren Protokollen gezeichnet wurden.

24 Stunden nach der Operation sind schon viele Polypen regenerirt, besonders an den apicalen Ästen (Textfig. 2). Im weiteren Verlauf werden anch die ibbrigen Hydranten regenerirt, so dass unter günstigen

Fig. 1.

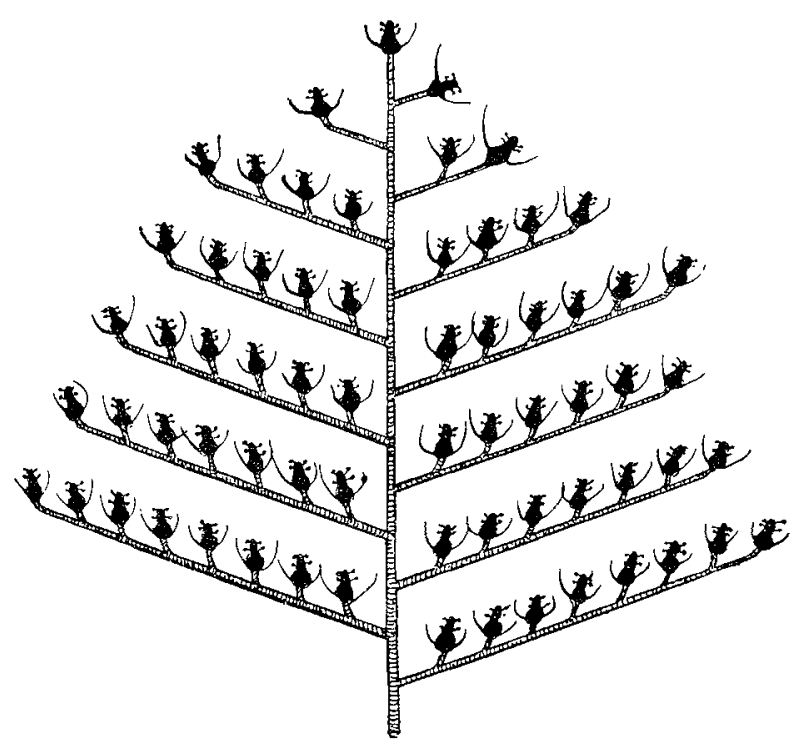

Fig. 1-3. Regenerationsverlauf an ganzem aufgehāngtem Stamm schematisch wiedergegeben.

Fig. 1. Der Stock vor dem Abschneiden der Hydranten.

Erklärung für Textfiguren 1-6,10-12, Umständen fast der ursprüugliche Za13-18:

Stamm voll Cönosark,

$\Longrightarrow$ Stamm ohne Cönosark,

(\%) neugebildeter Stamm,

(7) Hyarant,

Hydrant in Bildung,

每 Degenerationsstadien. stand vor der Operation erreicht wird.

Textfig. 3 stellt das Thier 48 Stunden nach der Operation in einem Stadium dar, bei dem ein Theil der Hydranten schon zurückgebildet wird. Während an den Seitenästen die Degeneration fortschreitet, wachsen an den beiden Stammenden die dort gebildeten Hydranten weiter vor (Textfig. 4-6). An dieser beiderseitigen Verlängerung des alten Stammes entstehen in derselben Ebene wie die alten Seitenäste beiderseits neue Seitenhydranten mit langen Stielen. Nach ungefähr 96 Stunden nach der Operation (Textfig. 4) sind 


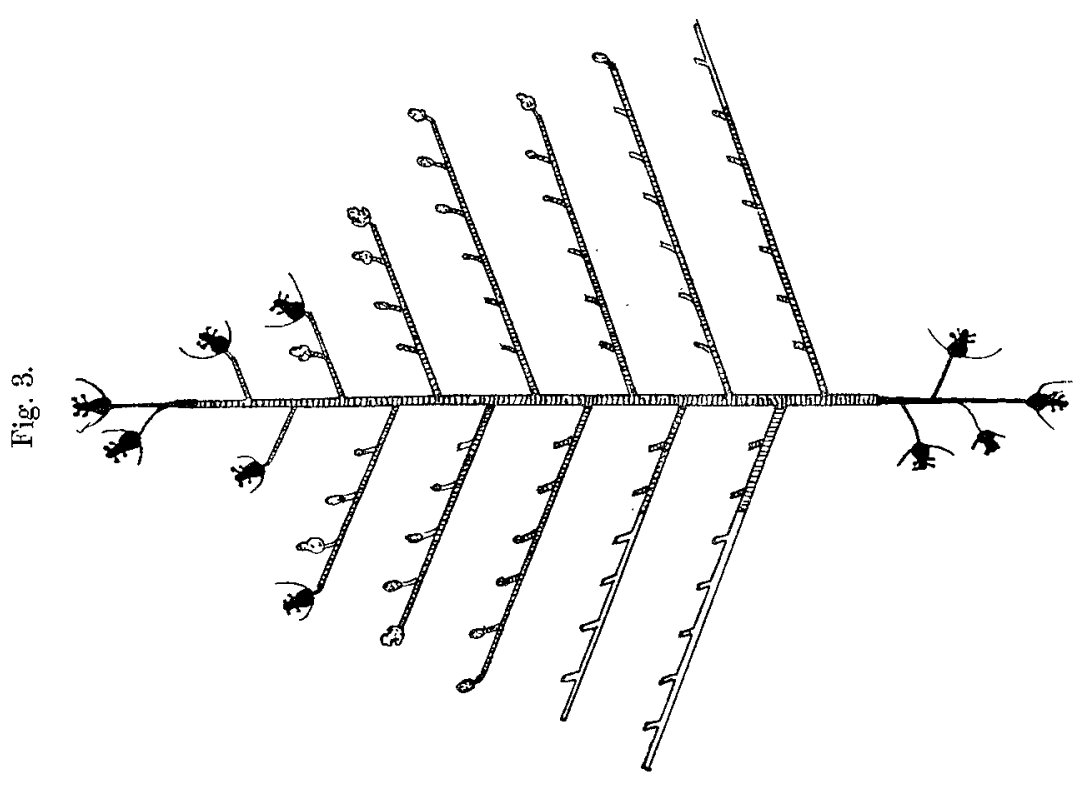

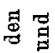

호

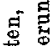

范

密

表

tis

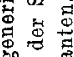

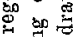

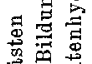

政

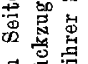

䗆

돌

席

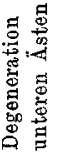

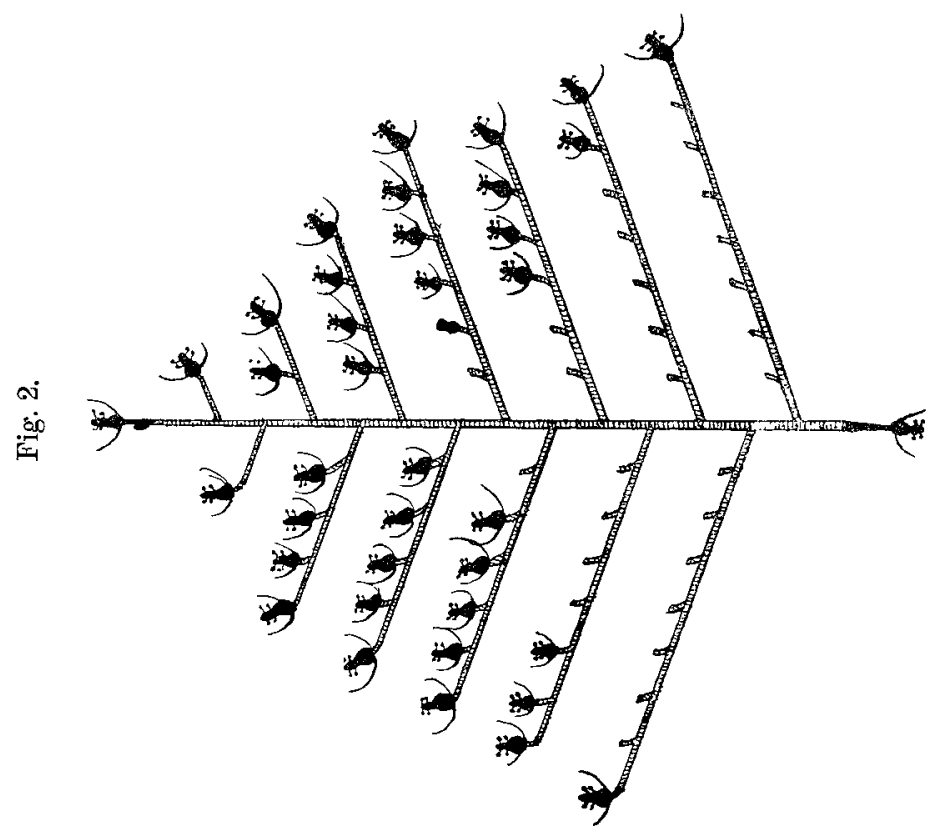



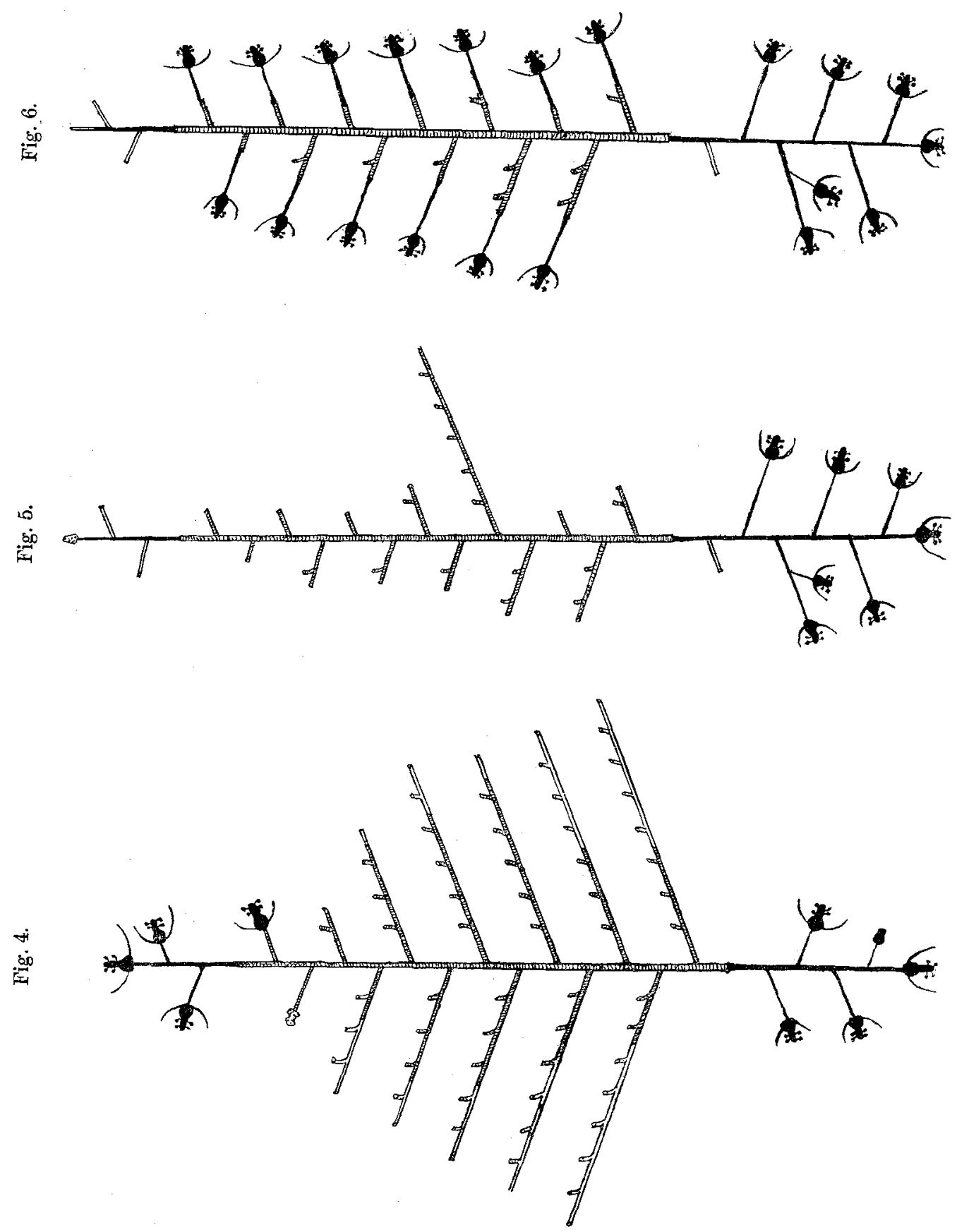
an den alten Seitenästen fast alle regenerirten Hydranten wieder verschwunden. In derselben Zeit löst sich in den Seitenästen das Cönosark von dem Perisark $a b$ und zieht sich nach dem Stamme zu zurïck, den größeren Theil der Äste und der Hydrantenstiele verlassend (vgl. Textfig. 4 links und rechts bei $a, b, e$ und $d$ die nicht schraffirten Aststiicke). Die leeren Perisarkröhrchen werden in ganz charakteristischer Weise abgetrennt und abgeworfen; Fig. 5 giebt das Bild wieder, nachdem dieses Abwerfen von Aststiicken schon vollzogen ist. An den Abtrennungsstellen werden dann wieder Hydranten regenerirt (Fig. 6). Wir haben hier kurz den ganzen Verlauf der Regulationserscheinungen geschildert, wie sie nach der Operation in den meisten Fällen bei PenFig. 7. naria beobachtet werden können.

Etwas anders stellt sich die formative Thätigkeit des Organismus dar, wenn der Stamm nicht aufgehängt, sondern auf den Boden des Gefäßes hingelegt wird. In diesen Fällen bildet sich an dem basalen Ende zuerst stets ein Stolo, welcher sich an dem Boden des Gefäßes festklebt und beim weiteren Wachsen in der Regel gabelt. In einigen wenigen Fällen zeigte sich, dass der auf dem Boden kriechende Stolo (Textfig. 7) sich an seinem freien Ende aufwärts bog: (Textfig. 8) und

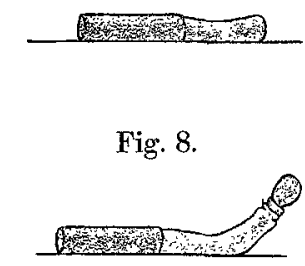
dann an diesem jetzt nicht mehr mit dem Boden in Berührung stehenden Ende einen Hydranten bildete (Textfigur 9).

Aus dieser Skizze sehen wir, dass hier folgende Processe sich abspielen: 1) Regeneration, 2) Degeneration der Hydranten, 3) die Verlagerung des Cönosarks, 4) das Abtrennen und Abwerfen der leeren Perisarkröhrchen und 5) die Bildung und das Wachsthum der neuen Sprossen mit den sekundären Seitenästchen. werden.

Alle diese Processe sollen im Folgenden genau beschrieben

\section{Regeneration der Hydranten.}

Die Regeneration der Hydranten geht bei Pennaria sehr schnell vor sich; schon nach 24 Stunden ist in der Regel ein Theil der Hydranten regenerirt. 
Wahrscheinlich ist auch die Jabreszeit, in der unsere Experimente angestellt wurden (Juni und Juli), für die Regeneration besonders günstig. Allerdings haben sich bei verschiedenem Material manche individuellen Differenzen gezeigt.

Pennaria stellt einen zusammengesetzten, aber doch einheitlichen Organismus dar. Durch Abschneiden von mehreren Polypen wurden dem Thier entsprechend viele Wunden beigebracht. Es fragte sich nun, auf welche von diesen Wunden der Organismus zuerst reagiren würde. Unsere Untersuchungen gaben in dieser Beziehung ganz sichere Resultate. An dem apicalen Ende und besonders an den apicalwärts gelegenen Seitenästen erscheinen die ersten Regenerationsprocesse. Erst später regeneriren die Hydranten an mehr basal gelegenen Seitenästen. In allen Fällen entstehen die ersten Hydranten apical, resp. an den Seitenästen distal; also lehrt die Beobachtung: der gesammten Äste eines Stammes, dass die Regeneration an den apicalen Ästen beginnt und damn basalwärts vorschreitend sich vollzieht. Jeder Seitenast des beobachteten Stammes für sich betrachtet, bietet dasselbe Bild des Regenerationsverlaufes: die Regeneration beginnt an der Spitze und schreitet stammwärts vor. Ein typisches Bild vom Regenerationsverlauf giebt Textfig. 2, welche schematisch das Resultat der Regeneration nach 24 Stunden darstellt. Man ersieht daraus, dass nur an den apicalen Ästen sämmtliche Hydranten wiedergebildet sind, dass aber an den basalen Ästen, so weit sie uiberhaupt regenerirt haben, nur die distalen Hydranten regenerirt sind. Erst im Laufe der nächsten 24 Stunden zeigen sich an den basalen Ästen noch eine weitere Anzahl never Hydranten. - Die Zahl der regenerirten Hydranten ist nicht konstant. Nach unseren Erfahrungen hängt das hauptsächlich von den individuellen Eigenschaften der einzelnen Thiere ab. Bei sehr kräftigen Individuen regeneriren alle abgeschnittenen Hydranten; ja wir haben sogar Fälle beobachtet, wo nach Wiederherstellnng aller abgeschnittenen Hydranten noch durch weiteres Wachsthum des Stammes und der neùgebildeten Seitenäste Platz für nene Hydranten geschaffen wurde und die Entwickelung derselben dann wirklich stattfand. So besaßen einzelne unserer Beobachtungsthiere nach Ablauf der Regeneration eine größere Hydrantenzahl, wie vor der Operation. In der Regel gelangen indessen nicht alle abgeschnittenen Hydranten zur vollständigen Ausgestaltung. Einige von ihnen - und hier immer die Hydranten an den basalen Ästen oder einige proximale Hydranten an anderen Seitenästen regeneriren überhaupt nicht, oder bleiben auf 
frühen Entwickelungsstadien stehen. Diese Variabilität in der Regenerationsleistung verschiedener Individuen lässt sich am besten durch folgende Beispiele demonstriren, welche unseren Protokollen entnommen sind:

\begin{tabular}{c|c|c|c}
\hline Nr. & $\begin{array}{c}\text { Zahl der } \\
\text { abgeschnürten } \\
\text { Hydranten }\end{array}$ & $\begin{array}{c}\text { Zahl der } \\
\text { regenerirten } \\
\text { Hydranten }\end{array}$ & $\begin{array}{c}\text { Regenerations- } \\
\text { ergebnis in Procenten } \\
\text { ausgedrückt }\end{array}$ \\
\hline 1 & 69 & 62 & $90 \%$ \\
2 & 87 & 69 & $79 \%$ \\
3 & 96 & 49 & $51 \%$ \\
4 & 25 & 18 & $72 \%$ \\
5 & 61 & 40 & $66 \%$ \\
6 & 89 & 50 & $56 \%$ \\
7 & 64 & 28 & $44 \%$ \\
8 & 68 & 37 & $54 \%$ \\
9 & 72 & 78 & $108 \%$ \\
10 & 60 & 37 & $62 \%$ \\
11 & 50 & 18 & $36 \%$ \\
12 & 65 & 41 & $63 \%$ \\
13 & 85 & 83 & $98 \%$
\end{tabular}

Das Mittel der regenerirten Hydranten beträgt also $67 \%$.

Aus dieser Tabelle ersehen wir, dass die Zahl der regenerirten Hydranten in der Mehrzahl aller Fälle größer ist als die Hälfte der urspringlichen Zahl and in dem einen angeftihrten Fall (Nr. 9) die Zahl der vor der Operation vorhandenen Polypen übertrifft. Diese Tabelle berïeksichtigt nur das Regenerationsergebnis vor Eintritt irgend welcher Degenerationserscheinungen. Zählt man auch die nach Verkürzung der Seitenäste (Textfig. 6) sich bildenden Hydranten und die an den neuen Seitenästen der Stammverlängerungen entstehenden Hydranten hinzu, so erhöht sich der Procentsatz in allen Fällen bedentend.

Zum Studium der Vorgänge bei der Hydrantenregeneration wurde der terminale Stammhydrant etwa $1 \mathrm{~mm}$ unter seiner Basis durch quergefiuhrten Scherenschnitt entfernt. Die erste Reaktion auf diese Verwundung besteht in einer Kontraktion des Cönosarks (Taf. II Fig. 1a). Die offenbar elastische Basalmembran (bas.M) zieht sich am weitesten zurück; die Ektodermzellen bleiben mit ihrer Basis im ursprïnglichen Kontalkt mit der Basalmembran, an der Perisarkfläche bleiben sie indessen noch haften, so dass die Wundfläche des Ektoderms nicht parallel zur quergeführten Schnittfläche liegt, sondern schräg nach innen abfällt. Die Entodermzellen bilden einen schwach 
gegen die Wunde vorgewölbten Wulst. Die nächsten Veränderungen erleiden die Entodermzellen. Der ebenerwähnte Zellwulst verdickt sich, so dass die Kommunikation des Körperlumens mit der Außenwelt sehr verengert ist (Taf. II Fig. 1b). Schon nach etwa 5 Minuten haben die Entodermzellen die Wunde geschlossen (Taf. II Fig. 1c). Anch die Ektodermzellen beginnen nun vorzuwachsen und sich von den Seiten her über die geschlossene Entodermkappe zu schieben (Taf. II Fig. 1d und c), während zu gleicher Zeit ein langsames Vorrüicken des Gesammtcönosarks nach der Perisarköffnung hin stattfindet. Auch nachdem das Ektoderm das Entoderm vollstïndig uiberwölbt hat, scheint ein starkes Vordrängen von Ektodermzellen stattzufinden; so wäre wenigstens leicht die jetzt eintretende sehr starke Erhöhung des Ektoderms zu verstehen (Taf. II Fig. 1f). Sobald das Cönosark den Wundrand überschreitet, schwillt die vorwachsende Cönosarkkuppe etwas an, wodurch das vorher zusammengepresste und in Folge dessen aus hohen cylindrischen Zellen sich zusammensetzende Ektoderm sich etwas abflacht. Das Entoderm der Knospe ist im Vergleich zum Stammentoderm etwas niedriger. Überall im Ektoderm vertheilt finden sich ansgebildete Nesselzellen und nahe der Basalmembran zahlreiche Entwickelnngsstadien derselben. Sehr bald bilden sich auch an der Basis der Knospe die charakteristischen Ringfalten (Taf. II Fig. 3 Rf, Fig. 7). Nun gehen im Ektoderm und Entoderm wichtige Veränderungen vor sich, während die ganze Knospe sich in die Länge streckt und durch Nachschub von Zellmaterial aus dem Perisark heraus langsam von der ursprïnglichen Wundfạ̈che entfernt. Im Ektoderm sondern sich die Anlagen der Basaltentakel und die der Knopftentakel und bilden hier flache halbkugelige Vorwölbungen. Sämmtliche große Nesselzellen verschwinden bald aus dem gesammten übrigen Ektoderm und finden sich nur in den Kopfanlagen der Hypostomtentakel. Die Basaltentakel bilden zunächst ebenfalls nur kleine Ektodermhöcker (Taf.' II Fig. 4), in die erst später ebeñso wie in die Anlagen der Hypostomtentakel das Entọderm hineinwächst und das charakteristische Tentakelgerüst liefert. $\mathrm{Zu}$ erwähnen wäre noch, dass die Außenseite der Basaltentakel dicht mit kleinen Nesselzellen besetzt ist. Abgesehen von der Bildung des Armgerüstes differenzirt sich das Entoderm nocb weiter, indem einzelne Zellkomplexe stark an Volumen zunehmen und falten- oder büschelfơrmig in die Hydrantenhöhle vorspringen, deren. Lumen oft fast vollständig füllend. Mit dem Durchbruch des Mundes ist dann die Ausgestaltung des Hydranten im Wesentlichen vollendet. 
Unmittelbar nach dem Wundverschluss scheiden die Ektodermzellen ein Perisarkhäutchen aus, das durch die vorwachsende Knospe mehr und mehr ausgedehnt wird und bald nachdem der Hydrant das auf Taf. II Fig. 4 abgebildete Stadinm erreicht hat, von dem vorwachsenden und an Volumen zunehmenden Hydranten zersprengt wird.

\section{Die Degeneration der Hydranten.}

Durch die regenerativen Processe wurden die abgeschnittenen Polypen resp. eine Anzabl derselben wieder hergestellt. Aber dieser Zustand bleibt nicht lange bestehen. Nach zwei oder drei Tagen beginnt die Degeneration der regenerirten Hydranten, ein Riuckbildungsprocess, durch den alle Polypen wieder zu Grunde gehen. Es ist dies kein Abfallen der lebenden Hydranten, wie bei Tubularia; dort werden durch Autotomie noch lebenskräftige oder absterbende Hydranten rom Stamm abgelöst. Hier bei Pennaria bleiben die Hydranten während des ganzen Degenerationsverlaufes in ihrem ursprünglichen Zusammenhang mit dem uibrigen Cönosark. - Die morphologischen Veränderungen, welche bei der Rückbildung der Hydranten wahrnehmbar sind, sollen Fig. 7-12 auf Taf. III veranschaulichen. Die ersten Veränderungen machen sich äußerlich durch Verkürzung des ganzen Hydranten und Schließen des am distalen Hydrantenende gelegenen Mundes bemerkbar. Dass aber auch im Inneren des degenerirenden Hydranten schon in diesem friben Stadium histolytische Vorgänge stattfinden, kann man in einigen Fällen, in denen durch irgend welche Umstände das Schließen des Mundes verzögert wurde, dadurch erkennen, dass aus dem geöffneten Munde langsam ein Strom von kleinen Körnchen herausquillt. Dieses Ausströmen von Körnchen erinnert an die von Miss Stevens bei Tubularia beschriebene Erscheinung des Ausstoßens der rothen Pigmentkörnchen. Die ausströmenden Körnchen sind hier als Zerfallsprodukte gewisser Zellelemente zu betraehten. Während die Verkürzung des Hydrantenkörpers langsam fortschreitet, verändern die Knopftentakel und ebenso die langen Basaltentakel ihre Gestalt, sie scheinen langsam in den Hydranten zu "versinken* (Taf. III Fig. 7 bis 9). Dieses Einziehen der Tentakel in den Hydrantenkörper lässt sich besonders gut an den Knopftentakeln beobachten. Der Nesselzellen tragende Tentakelkopf bleibt zunächst noch vollständig unverändert, während sich sein Stiel mehr und mehr verkürzt, bis der Kopf kugelförmig der Hydrantenoberfläche aufsitzt. Diese kugelförmigen Erhebungen verschwinden 
allmählich. In ähnlicher Weise verschwinden auch die Basaltentakel, welche zuletzt einen Kranz von kleinen Höckern bilden. Nach dem Versehwinden der Tentakel hat der degenerirende Hydrant eiförmige Gestalt mit glatter Oberfläche und sitzt mit dem einen Pole dem Hydrantenstiel auf (Taf. III Fig. 10). Nach und nach schrnmpft dieser Rest zu einem kleinen kugelförmigen Gebilde zusammen, dessen Durchmesser kaum größer ist wie der des $\mathrm{Hy}$ drantenstieles (Taf. III Fig. 11). Die nur noch schmale Verbindung mit dem Cönosark wird zerrissen (Taf. III Fig. 12) und der Restkörper fällt auf den Boden, wo er vollständig zerfällt. Abgesehen von diesen Formveränderungen zeigen sich am lebenden in Degeneration befindlichen Hydranten noch Veränderungen seiner Färbung. Es erscheinen durch die Oberfläche durchschimmernd rostbraune Flecke verschiedeuer Größe (vgl. Taf. III Fig. 9-12), die im Laufe der Degeneration an Verbreitung zunehmen und dem degenerirenden Hydranten ein ganz charakteristisches Aussehen verleihen, wodurch es ermöglicht wird, einzelne Degenerationsstadien von sehr ähnlichen Entwickelungsstadien zu nnterscheiden.

Die sich im Inneren des degenerirenden Hydranten abspielenden Vorgänge wurden an Schnittserien untersucht. Taf. III Fig, 13 giebt einen Medianschnitt durch den in der Fig. 7 auf Taf. III abgebildeten Kopf wieder. Die hauptsächlichsten Veränderungen betreffen die Entodermzellen. Ihre Kontouren verwischen sich, das grobkörnige Plasma ist von Vacuolen durchsetzt, man trifft oft degenerative Fragmentation der Kerne, und diese Degenerationsprodukte werden aus dem Zellkörper in den Hydrantenhohlraum ausgestoßen. Diese Degeneration ist dem Process sehr ähnlich, der von Miss Stevens zuerst für Tubularia angegeben und von einem von uns bei der Beschreibung der Regeneration der längsgespaltenen Stämme bestätigt wurde. Auch ganze Entodermzellen lösen sich von der Basalmembran los und flottiren mit den ibrigen degenerirten Plasmatheilen in der Leibesflüssigkeit. Die nächsten Veränderungen betreffen die Ektodermzellen, zuerst die der Tentakel. Ihre Basalmembran obliterirt und dann treten die ektodermalen Zellen aus ibrem Verbande heraus und in die Hydrantenhöhle über.

Dieses Auswandern von Ektodermzellen in den Körperhohlraum findet am stärksten an der Tentakelbasis statt, so dass zuletzt erst die Tentakelspitze, resp. die mit den großen Nesselzellen dicht besetzten Tentakelköpfe der oralen Tentakel verschwinden. Dass die Ektodermzellen sich nicht etwa auf der Hydrantenoberfläche vertheilen, sondern 
wirklich in den Körperhohlraum übertreten, dafür ist, ein sicherer Beweis der Umstand, dass die gegen Degeneration sehr widerstandsfähigen Nesselzellen sich meist recht zahlreich unter den anderen Degenerationsprodukten im Hydrantenhohlraum vorfinden. Da Nesselzellen nie im Entoderm vorkommen, können sie nur aus dem Ektoderm ausgewandert sein. Auch an anderen Stellen des Hydranten wird das Auswandern von Ektodermzellen nach innen durch stellenweises Auflösen der Basalmembran vorbereitet.

Der nächste auf Taf. III Fig. 14 abgebildete Medianschnitt entspricht dem auf Taf. III Fig. 8 gegebenen Totalbild. Die Knopftentakel sind nur. noch schwache Vorwölbungen des Ektoderms, ebenso die höckerförmigen Basaltentakel. Die Entodermzellen sind zum größten Theil degenerirt und die Basalmembran ist vollständig verschwunden. Die Ektodermzellen fangen an sich abzuplatten. Da dabei die Gesammtoberfläche des Hydranten sich kontinuirlich verkleinert, ist die Abplattung der Ektodermzellen nur dadurch möglich, dass ein großer Theil der Zellen in die Fliussigkeit auswandert, welche den Hydrantenraum ausfüllt und dort im Verein mit den übrigen Plasmakörnchen, Kernfragmenten, Nesselzellen etc. cirkulirt. Von Beginn der Degeneration an kann man nämlich am lebenden Objekt im durchsichtigen Hydrantenstiel eine lebhafte Körnchenströmung beobachten, an der auch die Degenerationsprodukte des Hydranten Theil nehmen. Die Richtung des Stromes wechselt. Finmal sieht man die Körnchen stammwärts vom Hydranten ausströmen, dann tritt eine kürzere oderlängere Pause ein und endlich sieht man die Masse wieder zurückströmen. Besonders gut lassen sich die stark farbstoffhaltigen and dadurch sehr auffälligen Plasmapartikel bei der Strömung verfolgen. Man sieht sie aus dem Hydrantenkörper in den Stiel (Taf. III Fig. 16) übertreten, dort im Wirbel ein Stïck forttreiben, Halt machen, und endlich bei der Rückströmung nicht selten wieder in den Hydranten eintreten. - Das nächste Stadium (Taf. III Fig. 16 ein Medianschnitt durch den anf Taf. III in Fig. 10 abgebildeten Hydranten) zeigt keine Spur irgend welcher Tentakelreste mehr. Das Ektoderm bildet zum größten Theile eine flache Schicht von Zellen, denen in unregelmäßigen Haufen innẹ die Reste der Entodermzellen anliegen, so weit diese nicht im Hohlraum frei flottiren. Nur der basale Theil des Hydrantenektoderms ist noch nicht so weit in der Degeneration fortgeschritten. Im nächsten Stadium (Taf. III Fig. 17 Medianschnitt durch den in Fig. 11 abgebildeten Restkörper) unterliegt auch dieser der Degeneration. Der Hydrant bildet eine 
kleine Kugel, nach außen von einer flachen Ektodermschicht begrenzt, innen von einer unregelmäßigen Masse von Degenerationsprodukten erfuillt. Zwar steht diese Kugel noch mit dem Cönosark des alten Hydrantenstiels in Verbindung, aber dessen Lumen ist an der Verbindungsstelle geschlossen. Jetzt beobachtet man am Asteönosark langsame Kontraktionen; der schmale, das Cönosark mit dem Restkörper des Hydranten verbindende Strang zieht sich oft fadenförmig aus, bis er ganz zerreißt und das dem Stielperisark aufsitzende Kügelchen ohne jede Verbindung mit dem Cönosark lässt (Taf. III Fig. 12). Nach kurzer Zeit fällt der Restkörper ab und geht vollständig zu Grunde. Nur in einigen wenigen Fällen wurde beobachtet, dass der Durchmesser des kugelförmigen Hydrantenrestes so klein war, dass der letztere bei den Kontraktionen des Cönosarks in den Hydrantenstiel hineingezogen werden und dem Rückzug des Cönosarks folgen konnte. Was später aus diesem letzten Rest geworden ist, ob er innerhalb des Perisarks noch abgestoßen, oder dem Cönosark einverleibt wurde, ließ sich nicht feststellen.

Bei Beobachtung dieser Hydrantendegeneration drängt sich die Frage auf, ob hier eine Analogie mit der durch LoEB (1900) von Campanularia beschriebenen Transformation des Hydranten in den Stamm vorliegt. Die Unterschiede scheinen jedoch ganz wesentlich zu sein. LoEB giebt nämlich an, dass bei Campanularia die Tentakel mit einander zu einer homogenen Masse verschmelzen: „Very soon all the tentacles beginn to fuse into a homogeneous mass. " Etwas Ähnliches kommt bei Pennaria nie vor. Die Tentakel werden zwar in den Hydrantenkörper hineingezogen, aber bis zum letzten Augenblick ihrer Existenz bleiben sie von einander getrennt. Ein anderer Unterschied besteht darin, dass fast in allen Fällen ein Überrest des degenerirten Hydranten zurückbleibt und später abfällt. Bei Pennaria also kann von einer direkten Transformation des Hydranten in den Stamm, wie es bei Campanularia vorkommen soll, nicht gesprochen werden. Man kann nur mit gewisser Wahrscheinlichkeit vermuthen, dass einzelne Bestandtheile der degenerirten Hydranten in Gestalt grober Körnchen (farbloser oder farbstoffhaltiger Degenerationsprodukte von Plasma und Kernen) mit der strömenden Flüssigkeit in das Lumen des Stammes hineingerathen und von den Cönosarkzellen resorbirt werden. Nur in sehr seltenen Fällen können die Restkörperchen der Hydranten in das Perisark hineingezogen werden, ob aber. die sie zusammensetzenden Zellelemente als Zellen weiter Verwendung finden, ist ungewiss. - Die Degenerationsprocesse, welche hier geschildert 
worden sind, treten bei allen Polypen eines Individuums auf. Wie wir früher gesehen haben, schreiten die Regenerationsprocesse von den distalen Enden proximalwärts vor. Wie verläuft nun die Degeneration? Kann hier auch eine gewisse Regelmäßigkeit im Vorschreiten der Degeneration an allen Hydranten festgestellt werden oder nicht? Unsere Beobachtungen haben ergeben, dass in der Mehrzahl aller Fälle die Degeneration in entgegengesetzter Richtung vorschreitet wie die Regeneration. Zuerst degeneriren die zuletzt regenerirten Hydranten. Wir sehen also, dass die Degenerationserscheinungen zuerst an den basalen Seitenästen und zwar bei den proximalen Hydranten auftreten, dann nach und nach auf die apical gelegenen Äste übergreifen und auch an diesen proximalsten $\mathrm{Hy}-$ dranten beginnend distalwärts vorschreiten. - Nicht immer ist der Verlauf der Degeneration so schematisch, wie eben skizzirt. In einzelnen Fällen degeneriren distale Hydranten eher wie proximale, oder an apicalen Ästen zeigen sich einzelne degenerirende Hydranten, während die der basalen Äste noch vollständig intakt sind. Das sind aber immer nur einzelne Ausnahmen. - - Die schematische Darstellung des Verlaufs der Degeneration ist auf Textfigur 3, nach dem Protokoll eines unserer Versuche, wiedergegeben. Das Schema stellt das Thier vor in dem Moment, wo die Polypen an den basalen Seitenästen degenerirt und abgefallen, an den mehr apical gelegenen Seitenästen aber noch größtentheils in Degeneration begriffen sind. Nur die terminalen Polypen sind noch intakt geblieben.

\section{3: Die Verlagerung des Cönosarks.}

Es wurde schon in der allgemeinen Skizze der Regulationserscheinungen erwähnt, dass gleich nach der Degeneration der Hydranten sich das Cönosark aus den Hydrantenstielen und dem distalen Theil der Äste zurückzieht. Dieses Cönosark wird in andere Theile des Thieres verlagert and seine Zellelemente werden für die weiteren formativen Processe verwendet. Das Zurückziehen des Cönosarks geschieht nicht gleichzeitig in allen Seitenästen und beginnt oft an den basalen Ästen schon zu einem Zeitpunkt, wo die Degeneration der Hydranten an den apicalen Seitenästen noch nicht vollendet ist. Nicht selten sind jedoch Fälle, bei denen an den basalen Ästen Regeneration von Hydranten iiberhaupt nicht stattfindet und ihr Cönosark schon anszuwandern beginnt, während an den apicalen Ästen die Regeneration noch im Gange ist.

Die Cönosarkwanderungen finden innerhalb des alten Perisarks 
statt. Wenn durch den Cönosarknachschub das an anderen Stellen des Thierkörpers verfügbar werdende Material aus den Öffnungen der Hydrantenstiele oder der Stammenden hervortritt, so umgiebt es sich sofort durch Ausscheidung auf der Oberfläche der Ektodermzellen mit neuem Perisark. Die Erscheinung des Zuriickziehens des Cönosarks wird besonders an den Seitenästen leicht beobachtet, kommt aber auch oft im Hauptstamm, besonders an seinem apicalen Theile, vor. Die Thatsache, dass während der Regeneration an einer Stelle des Thieres Verlagerung der lebenden Elemente stattfinden kann, ist schon in der Litteratur erwähnt worden. So schreibt W. Roux ${ }^{1)}$ : $»$ Es giebt also eine Regeneration durch ausschließliche oder überwiegende ,Umordnung" und ,Umdifferenzirung" von Zellen ohne oder mit nur geringer "Proliferation' bei der Regeneration."

Weitere Mittheilungen bringt Miss Perbles. Bei der Beobachtung der Regenerationsprocesse, welche sich an abgeschnittenen Tentakeln von Hydra abspielen, hat Miss Peebles bemerkt, dass: »The endoderm of the body part appears to be gradually crawling from the region of the hypostome down into the tentacles.

In seiner Monographie über organische Regulationen hat DrIESCH auf die Bedeutang dieser Processe hingewiesen und dabei die betreffende Litteratur besprochen.

Aber die wichtigsten Angaben, die wir in dieser Beziehung haben, stammen von J. Loki (1900). Der genannte Forseher hat bei Campanularia in der Zeit der regenerativen Bildnng der neuen Stolonen die Verschiebungen von Cönosark im Perisark beschrieben und abgebildet. Diese Thatsachen von Cönosarkverlagerungen können wir auf Grund nnserer Beobachtungen bei Pennaria vollkommen bestätigen. Besonders in der Ausdehnung und in der unzweifelhaften Dentlichkeit, wie die Cönosarkwanderung bei Pennaria vorkommt, sind diese Verlagerungsprocesse wahrscheinlich selten zu treffen.

Durch das ziemlich durchsichtige Perisark kann man genau verfolgen, wie sich das Cönosark rom distalen Ende der Seitenäste zurickzieht, so dass das Perisark vollkommen leer bleibt. Bevor der Process der Cönosarkverlagerung eingetreten ist, füllt das Cönosark die Perisarkröhrchen vollständig aus. Zwischen ihm und der Wandung der letzteren ist kein Zwischenraum vorhanden. Sobald aber an den einzelnen Wundstellen das Cönosark zur Bildung der Hydranten sich vorschiebt, verringert sich innerhalb des Perisarks der

1) W. Roux, Gesammelte Abhandlungen. II. pag. 836. 
Querschnitt des Cönosarks oft bis auf $1 / 3$ seiner Größe. Das Ektoderm zieht sich erst stellenweise, dann aber fast vollständig rom Perisark zurück und das Cönosark durchzieht frei als Cönosarkstrang die Perisarkröhrchen. Nur an einzelnen Stellen sieht man von den ektodermalen Zellen feine plasmatische Ausläufer ausgehen und als zarte Verbindungsbrücken zwischen Perisark und Cönosark bestehen bleiben (Taf. II Fig. 9 C.-Br). Auch diese feinen Bruicken köunen in das Ektoderm eingezogen werden.

Die Beobachtung am. Iebenden Material hat uns iberzeugt, dass das Zurückziehen vom Cönosark innerhalb des Perisarks durch aktive Kontraktion des Cönosarks zu Stande kommt. Diese Kontraktionen treten oft krampfhaft auf, so dass man plötzlich das ruckweis erfolgende Zurïckziehen des Cönosarks auf ziemlich langer Strecke beobachten kann; diese Kontraktionen wiederholen sich in kurzen Pausen. In anderen Fällen findet die Kontraktion langsam und gleichmäßig statt. Wir haben endlich auch Fälle beobachtet, wo nach der Kontraktion das Cönosark sich wieder vorschob und seinen Platz, den es vor der Kontraktion einnahm, fast wieder erreichte. Bei dem Zurückziehen des Cönosarks bleibt sehr oft an seinem vom Perisark vollständig losgelösten Ende ein kürzerer oder längerer Zapfen (Taf, II Fig. 9 C.Z) zurück, welcher entweder nur aus ektodermalen Zellen, aus Entodermelementen oder aus beiden. Zellschichten besteht und natürlich später auch in die Hauptmasse des Cönosarks eingezogen wird.

In ganz ähnlicher Weise wie am Seitenastende gestaltet sich auch der Cönosark-Rückzug nach der Degeneration und dem Abfall der Hydranten in den einzelnen Hydrantenstielen. Auch hier wird zuerst der Zusammenhang des Cönosarks mit dem Perisak gelockert (Taf. II Fig. 9a), die einzelnen Brücken werden nach und nach in das Ektoderm einbezogen, bis das Cönosark ohne jede innige Verbindung mit dem Perisark bleibt (Taf. II Fig. 9b). Die Elemente der Stielbasis werden nach und nach von dem Astcönosark übernommen, wobei natürlich die Ektodermzellen in die Ektodermschicht, die Entodermzellen in die Entodermschicht des Astcönosarks übergehen. An jeder Abgangsstelle des Seitenastes resp. Hydrantenstieles finden also Zellumlagerungen statt; die Zellen müssen »umgeordnet (Roux) werden, um in den Seitenast resp. Hauptstamm gelangen zu können. An Schnittpräparaten sind derartig sich umordnende Zellen an den Abgangsstellen der Seitenäste da, wo diese mit dem Hauptstamm einen spitzen Winkel bilden, an ihrer Schrägstellung zu erkennen. Während 
so das Cönosark des Seitenastes an Zellelementen zunimmt, nimmt die Zahl der Zellen im betreffenden Stiel, der zurückgezogen wird, mehr und mehr ab, das Stieleönosark verkürzt sich und erscheint endlich als kurze Ausstülpung des Astcönosarks (Taf. II Fig. 9, bei $c$ ), bis anch dieser Rest vollständig in das übrige Cönosark durch Umordnung seiner Elemente ïbergeht.

In Zusammenhang mit diesen Verlagerungserscheinungen, welche, wie wir eben gesehen haben, sich durch Zurückziehen von gewissen Cönosarkpartien bethätigen, steht auch der ganze Vorgang des Wachsthums in. der Zeit der regenerativen Thätigkeit des Organismus. Das Wachsthum eines Organs kann durch Vermehrung des Zellvolumens, durch Zelltheilung oder durch Zellumlagerungen vor sich gehen (vgl. Driesch, Analytische Theorie der organischen Entwickelung). Unsere Beobachtungen sprechen bei den regenerativen Wachsthumsvorgängen bei Pennaria zu Gunsten der letzteren Wachsthumsmöglichkeit, also für Wachsthum durch Umlagerung schon vorhandener Elemente, außerdem aber auch für Wachsthum durch Veränderung der Zellformen. Karyokinetische Figuren haben wir nur hier und da ausschießlich bei Hydrantenbildung angetroffen. Dagegen waren im Stamm an den Stellen, wo Wachsthum sicher vorhanden war, in den betreffenden Schnittpräparaten alle Kerne in Rube: Wachsthum durch Zelltheilung kommt also hier nicht in Frage.

Wir haben gesehen, dass von verschiedenen Hydrantenstielen das Cönosark in die Seitenäste, von Seitenästen in den Hauptstamm verlagert wurde. Da natiirlich während dieses Vorganges die Perisarkröhre des Hauptstammes ihre Dimensionen beibehalten hat, so müssen sich in ihr die Zellelemente in komprimirtem Zustande befinden.

Kommt es in diesen komprimirten Zellen an irgend einer Stelle zu einer Expansion, so dass die vorber hochcylindrischen Zellelemente stellenweise mehr abgeplattet erscheinen, so müssen die benachbarten Zellgruppen entweder komprimirt oder, wenn sie dem Druck ausweichen können, vorgeschoben werden; das letztere macht sich an den Wundöffnungen durch Hervortreten des Cönosarks bemerkbar. Hier wird es zu Hydranten, resp. neuen Stämmen differenzirt.

So verlaufen die regenerativen Wachsthumsvorgänge in den Stämmen mit den Seitenästen. Untersucht man die Wachsthumsprocesse an Stammstïcken, deren Seitenäste abgeschnitten wurden, so kann man ebenfalls feststellen, dass das Wachsthum ohne Zellvermehrung vor sich geht. Hier werden zwar die Perisarkröhren vom Cönosark 
nicht stellenweise verlassen, aber das Wachsthum beruht auch hier auf Veränderung der Zellenform. Wenn sich nämlich die cylindrischen Zelien stark abplatten, so sind für die Zusammensetzung eines Cönosarkrohres von bestimmter Länge viel weniger Zellelemente nothwendig wie vorher, als die Zellen ihre hochcylindrische Form hatten; dadurch werden von der ursprïnglichen Zellenmenge eine Anzahl verfügbar, welche an der Wundstelle sich hervorschieben und dort differenziren. Dieses Abplatten der Zellen innerhalb des alten Perisarkrohres ist sehr deutlich auf den Präparaten zu beobachten, die von Stammstiicken bald nach der Operation hergestellt wurden. Dabei ist anch noch zu berücksichtigen, dass sich der Cönosarkstrang innerhalb des Perisarks bedeutend verdünnt, wodurch auch wieder Zellelemente als Wachsthumsmaterial verfügbar werden. Als Beispiel des Wachsthums durch Abplattung der Zellelemente kann der Fall dienen, wo aus dem Perisark eines kurzen Stammstiicks (Textfig. 20 und 21 anf pag. 109) beiderseits das Cönosark herausgewachsen ist. Die histologische Untersuchnng hat nachgewiesen, dass die Zellkerne keinerlei Theilungserscheinungen nachweisen und dass nur die Zellelemente innerhalb des alten Perisarks an Höhe bedeutend abgenommen haben und sich ans urspriinglich hochcylindrischen jetzt zu ganz platten Zellen umgeformt haben.

Bei dem Vorgange des Cönosarkvorschiebens aus der alten Perisarkhülle würde das Ektoderm ohne schützende Hülle bleiben, wenn nicht die Ektodermzellen stets, sobald sie mit der Außenwelt in direkte Berührung treten, neues Perisark ausschieden. Dieses Ausscheidungsprodukt zeigt sich zuerst als äußerst feines Häutchen, das durch fortwährende Ausscheidung neuer Perisarklamellen von Seiten der Ektodermzellen langsam an Dicke zunimmt. Das Wachsthum des Perisarks in die Dicke findet also durch Apposition statt. Die einzelnen Schichten haben oft nicht die gleiche Dichte und Färbung. Wie Fig. 1 auf Taf. III zeigt, ist hier eine mittlere Zone des Perisarks dunkler gefärbt, wie die äußere und innere Zone. Junges Perisark ist am lebenden Thier hell weißlich, während die Farbe des älteren Perisarks vom hellen Gelb bis zum dunklen Braun iubergeht. Aus der gesehilderten Art der Perisarkausscheidung ist es erklärlich, dass die Dicke des Perisarks an jungen Stammtheilen, resp. an den Spitzen der Seitenäste geringer wie an älteren Partien des Thierstocks ist. Auch das sich zurückziehende Cönosark scheidet bei dem oft ruckweise oder periodenweise vor sich gehenden Rückzug in den Momenten der Ruhe an dem freien Ende ein Häutchen aus. 
Die einzelnen Perisarkhäutchen sitzen dann tütenf̣̂̀rmig in einander (Taf. III Fig. 1):

\section{Spontanes Abtrennen leerer Perisarkröhrchen.}

Auf die Cönosarkwanderung folgt der charakteristische Process des spontanen Abtrennens der vom Cönosark verlassenen Perisarkabschnitte. Wie wir gesehẹn haben, ist das Cönosark im Rückzuge entweder ganz vom Perisark losgelöst oder doch nur durch schmale plasmatische Brïcken damit verbunden. An der Stelle, wo die Abtrennung der leeren Perisarkröhre erfolgen soll, beginnt dann die Cönosarkspitze wieder anzuschwellen, bis rings der Kontakt mit dem Perisark wieder gewonnen ist (Taf. III Fig. 2). Sobald dies geschehen ist, wird allmäblich in der Höhe des Kontaktes des Cönosarks mit dem Perisark ein änßerst feiner, quer zum Stamm verlaufender heller Ring sichtbar, der mehr und mehr an Deutlichkeit zunimmt und endlich auf der Perisarkoberfäche als feiner Riss erscheint (Taf. III Fig. 2, 3 Per.Ri). Jetzt beginnt das Cönosark vorzuwachsen. und das abgetrennte Röhrchen vor sich her zu schieben (Taf. III Fig. 4). [Das letztere geschieht nur, wenn der abgetrennte Perisarkabschnitt kurz ist; längere Stuicke fallen meist sofort $a b$, sobald der Riss auch die Perisarkoberfläche ergriffen hat. In den Gefäßen, in denen die Experimente angestellt werden, findet man nach einigen Tagen stets eine Anzahl leerer, anf die eben beschriebene Weise abgetrennter Perisarkröhrchen an Boden liegen.] Sobald das Cönosark hervorwächst und zum Hydranten sich differenzirt, scheidet es auf der Oberfläche ein neues Perisarkhäutchen aus (Taf. III Fig. 5 and $6 \mathrm{Per} . H$ ), das erst später durch den Hydranten zersprengt wird. Nicht selten unterbleibt nach dem Abtrennen des Perisarks das Vorwachsen des Cönosarks; das letztere beginnt von Nenem sich vom Perisark loszulösen und weiter stammwärts zu wandern, um in einiger Entfernung vom ersten Abtrennungspunkte den Process des Abtrennens der verlassenen Perisarkröhre zu wiederholen.

Über den Mechanismus der Perisarkabtrennung geben klaren Aufschlnss Längsschnitte, die durch ein der Fig. 2 auf Taf. III entsprechendes Aststück geführt wurden (Taf. III Fig. 1). Hier sehen wir, dass in der Region des Kontaktes des Cönosarks mit dem Perisark eine Gruppe von Ektodermzellen ein ganz eigenthümliches Aussehen gewinnen (Taf. III Fig. 1). Die Zellen sind schlanker als ihre Nachbarzellen und sind mit ihren äußeren etwas zugespitzten Enden alle nach einer bestimmten engbegrenzten Perisarkstelle gerichtet, 
so dass ihre Gruppirung auf Längsschnitten sehr an Sinnesknospen (Geschmacksbecher) erinnert. Ein Querschnitt würde einen ununterbrochenen Ring derartig gruppirter Zellen zeigen. An der Stelle des Perisarks, auf die die eben beschriebenen Ektodermzellen mit ihren äußeren Enden hinweisen, ist der innere Perisarkkontour unterbrochen, es zeigt sich eine im vorliegenden Falle bis zur Mitte der Dicke der Perisarkhaut reichende Höhlung (Taf. III Fig. 1 Per.Hö), die natiirlich auch rings um die ganze Perisarkröhre verläuft und dem in in Taf. III Fig. 2 abgebildeten Ring entspricht. An Schnitten durch spätere Stadien sieht man die allmähliche Vergrößerung dieser Perisarkaushöhlung, die schließlich bis zur äußeren Perisarkfläche reicht und so das Abbrechen der leeren Perisarkröhre bewirkt.

Die histologischen Bilder lassen nur die eine Deutung des hier beschriebenen Vorganges der Perisarkabtrennung zu, nämlieh die der Perisarklösung. Ein mechanisches Aushöhlen des Perisarks ist desshalb ausgeschlossen, weil ein Kontakt der Zellspitzen mit dem Perisark an der Stelle, wo die Rinne gebildet wird, nur ganz kurze Zeit besteht. Für Perisarklösung dagegen spricht die Form der entstehenden Rinne, wie auch die typische Gruppirung sämmtlicher Zellelemente, welche mit ihren Spitzen gegen die betreffende Stelle zugewendet sind. Wie Fig. 1 auf Taf. III zeigt, ist der Querschnitt dieser Rinne nicht halbkreisförmig, sondern nach vorn und hinten ausgebuchtet. Die von den charakteristisch angeordneten Ektodermzellen ausgeschiedene Substanz löst zunächst einen kleinen Hoblraum im Perisark, der allmählich sich vergrößert. Natürlich wirkt das Lösungsmittel nicht nur in der einen Richtung nach außen, sondern muss auch das Perisark in der Richtung nach vorn und hinten lösen, wodurch dann die in Taf. III Fig. 1 abgebildete Form des Hohlraumes zu Stande kommt. Das lösende Sekret wird vermuthlich in äußerst feinen Tröpfchen ausgeschieden, da das Plasma der betreffenden Zellen nicht von Vacuolen durchsetzt ist. Nur in einem Falle war eine der Zellen durch eine große Vacuole fast auf das Doppelte ihres ursprünglichen Volumens aufgebläht. In den meisten Fällen findet unmittelbar, nachdem die Rinne auf der Perisarkoberfläche durchgebrochen ist, ein Vorwachsen des Cönosarks statt; die differenzirten Ektodermzellen nehmen wieder die Gestalt gewöhnlicher Ektodermzellen an und ebenso deren Funktion, Perisark anf ihrer Außenfläche auszuscheiden. Dass Ektodermzellen die Fähigkeit haben, eine Perisark lösende Substanz auszuscheiden, werden wir später noch an 
anderen Beispielen zeigen können. In dem Falle der Abtrennung leerer Perisarkröhren haben wir jedenfalls eine für den Gesammtorganismus sehr wichtige regulatorische Funktion der Ektodermzelle zu sehen. Auf eine eingehende Analyse der causalen Momente, die diesen Regulationsprocess bedingen, müssen wir verzichten. Nur wollen wir bemerken, dass nach unserer Ansicht der Vorgang dureh innere Faktoren verursacht wird. In der Regel ist die Abtrennung der leeren Perisarkröhren bei Individuen zu beobachten, die durch Regeneration zahlreicher Hydranten ihrem Cönosark zahlreiches Zellmaterial entzogen haben.

Die hier geschilderten regulatorischen Processe, welche das Abwerfen eines Theils von Perisark bewirken und die Verkleinerung. des ganzen Individuums zur Folge haben, zeigen in gewissen Beziehungen manche Analogie mit den Autotomie-Erscheinungen. Doch sind diese Processe in wesentlichen Stücken von einander verschieden. Die Autotomie-Erscheinungen sind von Grard in sehr zutreffender und übersichtlicher Weise gruppirt und klassificirt. Ferner hat Frederice wichtige Thatsachen gefunden und auch die physiologische Seite des Gegenstandes eingehender bearbeitet 1). Morgan hat in seiner Monographie über Regeneration die wichtigsten Autotomiefälle zusammengestellt und mit eigenen Beobachtungen und theoretischen Erörterungen ergänzt.

Aber eben aus diesen Litteraturangaben geht hervor, dass die Autotomie ein Process ist, bei welchem ein Theil des Organismus mit allen seinen Bestandtheilen vom Organismus abgetrennt wird. Bei den von uns beobachteten Vorgängen liegt die Sache anders. Hier wird nur Perisark abgetrennt, also nur ein Ausscheidungsprodukt vom Ektoderm, das Stütz- und Schutzorgan des Cönosarks, aus dem sich vorher die noch lebensthätigen Elemente das Cönosark - zurückgezogen haben.

Auch der Mechanismus des Vorganges selbst ist ein anderer. Bei dem Autotomieprocess wirken für die Abtrennung des bestimmten

1) Als Bestätigung von FreDERICQ's Entdeckungen über die Bedeutung des Nervensystems für die Autotomie könnten die Angaben von Przibram gelten. Wir sagen skönntenء, weil der Beweis schuldig geblieben ist, dass bei seinen Versuchen die erfolgte Antotomie auf Zerstörung des Nervensystems zurïckzuführen ist. Durch die ${ }$ Durchbohrung des Coxopoditen (oder größerer Abschnitte der Gliedmaßen)* wurden doch auch andere Organe zerstört, die vielleicht auch nicht ohne Bedeutung für die Autotomie sein könnten. Es scheint uns hier noch die histologische Untersuchung dringend nothwendig zu sein. Die hat aber Przibram »den Histologen ïberlassen $\propto$. (Przibram pag. 514.) 
Körpertheils zusammen sowohl dieser selbst, als auch der Gesammtorganismus, von dem der Körpertheil abgetrennt wird. So kommt die Antotomie bei Lacerta durch die Kontraktion der Muskeln, "une brusque contraction musculaire * (FrEDERICQ, pag. 766), die Antotomie bei Tubularia durch lokale Durchschniurung des Stammes etc. zu Stande. In unserem. Falle ist der abzutrennende Körpertheil bei dem Vorgang des Abtrennens nicht selbst mit thätig, sondern wird, nachdem das lebende Cönosark sich daraus zurïckgezogen hat, von diesem abgeschnitten. Mit diesen Bemerkungen glauben wir nachgewiesen zu haben, dass der von uns beschriebene Vorgang des Abtrennens der leeren Perisarkröhren nicht zu den bis jetzt als Autotomie bekannten Erscheinungen gehört. Wir haben es hier mit einer Regulationserscheinung zu thun, welche durch spontanes Abtrennen eines Theils der Stützorgane dem Thiere seine regenerative Thätigkeit fortzusetzen ermöglicht. Die Größe der abgetrennten Perisarktheile wechselt außerordentlich. In manchen Fällen werden nur kurze, kaum millimeterlange Stiuckchen, von den Hydrantenstielen oft nur einzelne Ringe abgetrennt; in den anderen Fällen wieder zieht sich das Cönosark direkt bis an das proximale Astende zurick und trennt dort den ganzen leergelassenen Ast ab. Nicht immer erfolgt auf die erste Abtrennung, wie schon erwähnt, ein Vorwachsen des Cönosarks, sondern dieses zieht sich von Nenem zurück und wiederholt den Abtrennungsprocess. In der Mehrzahl unserer Beobachtnngen bildet sich indessen an der von dem Thiere selbst geschaffenen Wundfläche eine Hydrantenknospe, die sich zum Hydranten entwickelt. Auch in den Fällen, wo durch spontanes Abtrennen ein kleinerer Theil des Astes abgeschnitten wurde und sich dort ein Hydrant bildete, wiederholt sich nach der Degeneration des Hydranten der Cönosarküückung und näher am Stamm das spontane Abtrennen des Perisarks ${ }^{1}$, worauf wieder eine Hydrantenbildung eintritt. Das Endergebnis dieser Erscheinungen für den Thierstock ist jedenfalls die Verkleinerung desselben.

1) Fül die von uns gefundenen Thatsachen kommt gar nicht in Frage, ob man annimmt, dass die Wunde selbst als Anregung zur Regeneration wirkt, wie gewöhnlich angenommen wird, oder ob das *Nichtvorhandensein der friher existirenden Nachbarschaft als Auslösungsmoment zu betrachten ist, wie das zuerst von W. Roux (1893, pag. 834) angegeben und von H. Strasser (1899) and DrIEsch (1901) weiter ausgeführt wurde. 


\section{Die Bildung neuer Sprossen resp. Stolonen.}

Gleichzeitig mit den hier beschriebenen Vorgängen spielen sich an dem basalen und apicalen Ende des Thieres andere formative Processe $a b$, nämlich die Bildung der neuen Sprossen, resp. Stolonen. Wie schon aus den Litteraturangaben (J. Loeb, Peebles) bekannt, hängt das davon $a b, o b$ die Wunde frei vom Wasser umspült ist, oder ob das Thier einen festen Gegenstand mit der Wundfläche berührt.

Wir wollen zuerst die Fälle behandeln, in denen das aufgehängte Thier nirgends mit festen Gegenständen in Berührung kommt. In diesen Fällen bildet das aus dem apicalen und basalen Stammende hervorwachsende Cönosark einen Hydranten, dessen Stiel länger und länger wird. Am apicalen Stammende handelt es sich bei dieser Hydrantenbildung um echte Regeneration, während die Bildung des basalen Hydranten als Heteromorphose ${ }^{1}$ ) aufzufassen ist. Während und nach der Entwickelung des Hydranten, die etwa 24 Stunden in Anspruch nimmt, wächst der Hydrantenstiel immer mehr in die Länge, und diese auswachsenden Stammverlängerungen verhalten sich in ihrem Wachsthum genau wie junge Stämme, deren Wachsthum oben (pag. 79) im Anschluss an die morphologischen Bemerkungen geschildert worden ist. An ihnen, sowohl an der apicalen, wie anch an der basalen Stammverlängerung, bildet sich in derselben Ebene, in der die alten Seitenäste vom Stamm abgehen, zunächst auf der einen Seite eine Knospe, die sich bei gleichzeitigem Wachsthum ibres Stieles zu einem Hydranten entwickelt. Zwischen Endhydrant und dem ersten Seitenhydranten auf der diesem gegenüberliegenden Seite bildet sich bald eine zweite Knospe. In derselben Weise setzt sich die Bildung der Seitenhydranten weiter fort.

Die Richtung des Wachsthums dieser sekundären Seitensprossen ist sehr charakteristisch. Aus den morphologischen Bemerkungen ist uns bekannt, dass die Seitenäste von dem Hauptstamm nicht im rechten Winkel abgehen, sondern dass der Seitenast mit dem apicalen Stammtheil einen spitzen Winkel bildet. Die apicale Stammverlängerung bildet in der Beziehung nur eine Verlängerung des alten Thieres,

1) Wir folgen hier der Definition von J. LoEB, der für solche Fälle den Ausdruck Heteromorphose gewählt hat, in denen die Polarität ungekehrt wurde. Den Ausdruck Heteromorphose gebraucht auch MongaN im Sinne von LoEB. Nur DrIesch und Herbst haben diesen Ausdruck für ganz specielle Fälle reservirt. 
d. $h$. die neuen Seitenäste gehen in derselben Richtung vom nenen Stamm ab, wie die alten rom alten Stamm. Die basale Stammverlängerung mit ihren neuen Seitenästen verhält sich, wie ein Thierstock für sich: Der Endhydrant ist die Spitze des nenen Thieres und bestimmt als solche durch seine Wachsthumsrichtung die Richtang der neuen Seitenäste nach dem oben genannten Gesetz, dass der Seitenast mit dem apicalen Stammtheil einen spitzen Winkel bildet. Stets liegen indessen alle neuen Seitenäste, sowohl die der apicalen, wie die der basalen Stammverlängerung in derselben Ebene, wie die des alten Stammes (vgl. die Schemata 3-6). Die Lage der Versuchsthiere hat, wie die verschiedensten Versuche gezeigt haben, keinen Einfluss auf die Wachsthumsrichtung der verschiedenen neugebildeten Theile. Unsere Versuche haben uns iiberzengt, dass der Geotropismus hier keine Rolle spielt. Nun bleibt das einzige übrig: diese Erscheinung mit der Polarität des Thieres zu erklären, also auf die inneren Faktoren zurückzuführen.

Die an den Stammverlängerungen neu gebildeten Seitenäste können wie die alten Seitenäste einseitig die tertiären Hydranten hervorsprossen lassen. Die Seite, auf der diese tertiären Hydranten hervorwachsen, ist ebenfalls durch den Endhydranten des Stammtheils, von dem die Seitenäste ansgehen, bestimmt: stets entspringen die tertiären Hydranten auf der dem Stammendhydranten zugewandten Seite dieser Äste (Textfig. 6). In Folge der geschilderten Wachsthumsverhältnisse kommt ein Zeitpunkt, wo der regenerirende Stock ein eigenthümliches Bild bietet: Die erste Serie der regenerirten $\mathrm{Hy}-$ dranten ist schon rückgebildet und abgefallen; die Seitenäste sind nach spontanem Ábtrennen der leeren Perisarkröhruchen stark verkürzt, während die an beiden Stammenden hervorgewachsenen Verlängerungen mit ihren neuen Seitenästen und den darauf sitzenden Hydranten den Eindruck machen, als ob auf dem alten Thierstamm apical und basal nene Thiere sich entwickelt hätten. Im weiteren Verlauf kommt es auch zu der Degeneration dieser neuen Hydranten, und das Thier ist nun nicht mehr im Stande, nene Polypen zu bilden.

Nur in einigen wenigen Fällen (wahrscheinlich waren die Versuchsthiere sehr lebenskräftige Individuen) haben wir den weiteren Vorgang der Regulationserscheinungen beobachtet. Aus der apicalen Hälfte des Thieres hatte sich das Cönosark zurückgezogen und ungefähr in der Mitte des Stocks wurde die ganze apicale Hälfte des Thieres sammt den Seitenästen abgetrennt. Von dieser Stelle wuchs 
dann eine Cönosarkknospe hervor, die sich zu einem Hydranten entwickelte.

Eine andere Versuchsanordnung war die, dass der operirte Thierstock so auf den festen Boden hingelegt wurde, dass das aus der Wunde hervorwachsende Cönosark den Boden berühren musste. In diesen Fällen bildete sich dort stets ein Stolo. Auch dann, wenn das Thier so aufgehängt war, dass es mit einer Wundfäche den Faden berihhrte, wuchs von der Wunde ans ein Stolo, welcher sich dem Faden anklebte. Der Mechanismus des sich Aufklebens muss auf eine Fähigkeit des frisch ausgeschiedenen Perisarks zurïckgeführt werden; die Zellen nehmen nicht Theil daran. Der vorwachsende Stolo ist, abgesehen von seiner Kuppe, mit dickem Perisark umgeben (Taf. II Fig. 5), das sich auf Schnittpräparaten durch geringere Färbbarkeit durch Eosin von dem älteren Stammperisark unterscheidet.

Oft gabeln sich die Stolonen mehrfach, besonders wenn sie auf einer ebenen Unterlage wachsen. Zuweilen biegt sich, wie schon oben erwähnt (pag. 83) ein auf dem Boden kriechender Stolo aufwärts und bildet dann einen Hydranten (Textfig. 7, 8 und 9).

Die Stolonen können ebenfalls wie die Hydranten entweder regenerativ oder heteromorphotisch zu Stande kommen. Wenn Stolonen sich am basalen Ende des Stammes entwickeln, dann ist dieser formative Process als regenerativ zu bezeichnen. Heteromorphotische Stolonenbildung kann man dadurch hervorrufen, dass man den Stamm mit den Seitenästen, deren Hydranten abgeschnitten worden sind, so aufhängt, dass Wundflächen der Seitenäste die Wand des Gefäßes berühren. Nach 24-48 Stunden ist der Faden, an welchem der Stamm hing, überflüssig geworden, da an allen Stellen, wo das hervorwachsende Cönosark die Glaswand berührte, Stolonen gebildet sind, die sich dort so festgeklebt haben, dass sie den Stamm halten. Unsere Experimente bestätigen also die Beobachtungen von LOEB, welcher schon vor einigen Jahren die heteromorphotische Stolonenentwickelung bei Pennaria festgestellt hat.

\section{Regulationserscheinungen an kleineren Stammstïcken mit Seitenästen.}

Als Ergänzung zu dem vorigen Kapitel mögen noch einige Bemerkungen über die Regeneration von Stammstücken folgen, die durch Zertheilen eines längeren Stammes gewonnen wurden.

Ein Stamm von 30-40 mm Länge mit 7-9 Seitenästen jeder- 
seits wurde in drei Fig. 10.

Stuicke zerlegt (Textfig. 10-12). An jedem Stiick blieben also ungefähr zwei oder drei Seitenäste beiderseits. Die Hydranten der Seitenäste wurden abgeschnitten und die einzelnen Stïcke in Gefäßen aufgehängt. Bei Individuen, die für die Regeneration gut disponirt sind, haben sich schon am nächsten Tage die Hydranten an den Seitenästen der Stämme in ziemlich bedeutender Menge entwickelt. Nehmen wir als Beispiel einen in drei Theile zerlegten Stamm, die wir als basales, mediales und apicales Stück bezeichnen (Textfig. 10-12). Bei der Kontrolle nach 24 Stunden bietet sich ein sehr charakteristisches Regenerationsbild: Das apicale Stiick hat die größte Zahl von Hydranten regenerativ zur Entwickelung gebracht, das mediale Stïck eine geringere Zahl und das basale in allen Fällen wieder weniger wie das mediale Stück. Am besten

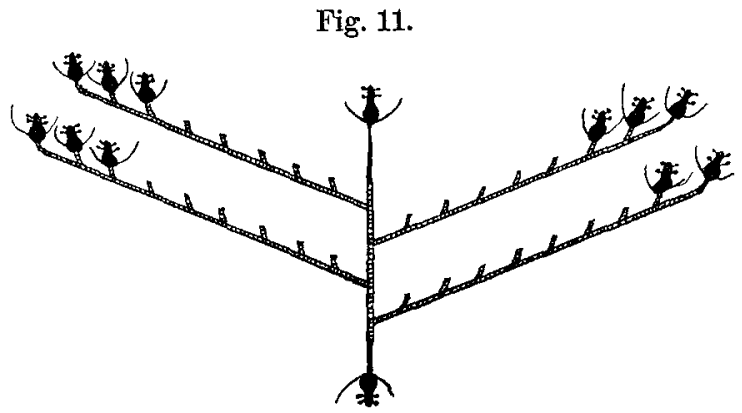

Fig. 12.

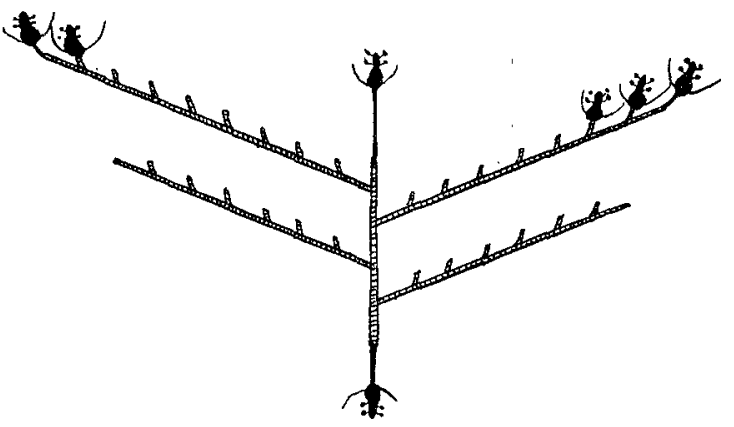

Ein Stamm in drei Stücke zerlegt, nach Abschneiden aller Hydranten anfgehängt und nach 24 Stunden gezeichnet (schematisch, nur die ganz entwickelten Hyaranten sind angegeben, unentwickelte Knospen nicht). Das Regenerationsergebnis an den Seitenästen ist am apicalen Stùck (Fig. 10) größer als beim medialen Stück (Fig. 11), dort größer wie bei dem basalen Stück (Fig. 12). Das Regenerationsergebnis an den stammenden ist umgekehrt bei dem basalen Stūck (Fig. 12) am größten, bei dem apicalen Stück Fig. $10 \mathrm{am}$ kleinsten. Vgl. Tabelle Nr. 1. 
lässt sich das durch Ziffern deutlich machen. Wir haben die Hydrantenzahl jedes Stüeks vor der Operation bestimmt and dann die Zahl der regenerirten Polypen nach 24 oder 48 Stunden festgestellt. In der folgenden Tabelle sind die Resultate einer Reihe derartiger Versuche und ihre procentuale Berechnung zasammengestellt.

Tab. 1. Kontrollresultate nach 24 Stunden.

\begin{tabular}{|c|c|c|c|c|c|c|c|c|c|}
\hline \multirow[t]{2}{*}{ Nr. } & \multicolumn{3}{|c|}{$\begin{array}{c}\text { Anzahl der abgeschnittenen } \\
\text { Hydranten am }\end{array}$} & \multicolumn{3}{|c|}{$\begin{array}{l}\text { Zahl dernach } 24 \mathrm{Stunden} \\
\text { regenerirten Hydranten am }\end{array}$} & \multicolumn{3}{|c|}{$\begin{array}{l}\text { Das Verbülttuis der Zahl der } \\
\text { regeneriirten Hydranten zu } \\
\text { den abgeschnittenen in Pro- } \\
\text { centen ausgedrückt }\end{array}$} \\
\hline & bas. St. & med. St. & apic. St. & bas. St. & med. St. & apic. St. & bas. St. & med. St. & apic. St. \\
\hline 1 & 30 & 34 & 31 & 5 & 12 & 13 & $17 \%$ & $35 \%$ & $42 \%$ \\
\hline 2 & 29 & 31 & 32 & - & 8 & 15 & $0 \%$ & $26 \%$ & $47 \%$ \\
\hline 3 & 69 & 41 & 43 & - & - & 8 & $0 \%$ & $0 \%$ & $19 \%$ \\
\hline 4 & 96 & 49 & 34 & 8 & 14 & 20 & $8 \%$ & $28 \%$ & $55 \%$ \\
\hline 5 & 59 & 52 & 27 & 一 & 6 & 17 & $0 \%$ & $12 \%$ & $63 \%$ \\
\hline 6 & 74 & 50 & 41 & 59 & 43 & 42 & $81 \%$ & $86 \%$ & $102 \%$ \\
\hline
\end{tabular}

Kontrollirt man die Versuchsstücke nach 48 Stunden, so ergiebt sich ein ähnliches Zahlenverhältnis zwischen den einzelnen Stïcken.

Tab. 2 (Nu. 1-3 sind dieselben Versuchsthiere wie Nr. 1-3 der Tab. 1). Kontrollresultate nach 48 Stunden.

\begin{tabular}{|c|c|c|c|c|c|c|c|c|c|}
\hline \multirow[t]{2}{*}{ Nr. } & \multicolumn{3}{|c|}{$\begin{array}{l}\text { Zahl der abgeschnittenen } \\
\text { Hydranten am }\end{array}$} & \multicolumn{3}{|c|}{$\begin{array}{l}\text { Zahl der naeh } 48 \text { Stunden } \\
\text { regenerirten Hydrauten am }\end{array}$} & \multicolumn{3}{|c|}{$\begin{array}{l}\text { Das Verhältnis der Zahl der } \\
\text { regenerirten Hydranten zu } \\
\text { den abgeschnittenen in Pro } \\
\text { centen ausgedrückt }\end{array}$} \\
\hline & bas. St. & med. St. & apic. St. & bas. St. & med. st. & apic. St. & bas. St. & med. St. & apic. st. \\
\hline 1 & 30 & 34 & 31 & 17 & 23 & 26 & $57 \%$ & $68 \%$ & $84 \%$ \\
\hline 2 & 29 & 31 & 32 & 12 & 26 & 30 & $41 \%$ & $84 \%$ & $91 \%$ \\
\hline 3 & 69 & 41 & 43 & - & 6 & 26 & $0 \%$ & $15 \%$ & $60 \%$ \\
\hline 5 & 47 & 38 & 33 & 7 & 22 & 30 & $15 \%$ & $58 \%$ & $91 \%$ \\
\hline 6 & 34 & 27 & 16 & 3 & 18 & 17 & $9 \%$ & $67 \%$ & $106 \%$ \\
\hline
\end{tabular}

Vergleicht man die in den letzten drei Kolumnen neben einander stehenden Ziffern, die in Procenten ausgedritckt den Effekt der Regeneration von hinter einander gelegenen Stücken eines Stammes geben, mit einander; so kommt man ohne Weiteres zu dem Schlusse, dass das Gewebe in den apicalen Ästen größeres Vermögen hat, Hydranten zu regeneriren, als das mediale und basale Stück, und dass ebenso die Regenerationsschnelligkeit basalwärts abnimmt.

Zu gleicher Zeit, in der an den Seitenästen der einzelnen Stücke 
die Hydrantenregeneration stattfindet, bilden sich an den beiden Enden jedes Stücks die Stammverlängerungen, die ihrerseits später in der oben beschriebenen Weise neue Seitenäste entstehen lassen. Wenn man die Summe der Regenerationsleistungen des betreffenden Stammstïcks beurtheilen will, so muss auch dieses Resultat der formativen Processe seine Berücksichtigung finden. Um dies anschaulicher zu machen, haben wir schematisch die Regenerationsleistungen bei den drei hinter einander gelegenen Stïcken eines Stammes an Textfig. 10-12 angegeben. Aus diesem Schema ersieht man, dass das apicale Stammstiick an den Seitenästen mehr Hydranten regene-rirt hat als das mediale und dieses wieder eine größere Anzahl als das basale, dass aber bei den letzteren die Stammverlängerung. an beiden Enden bedeutender ist wie bei dem medialen Stiick, bei diesem wieder größer als bei dem apicalen Stück.

Bei dem schematisch abgebildeten Fall war nach 24 Stunden am apicalen Stïck $4 \mathrm{~mm}$, am medialen $10 \mathrm{~mm}$ und am basalen $12 \mathrm{~mm}$ Stammverlängerungen gebildet. Ein ähnliches Verhältnis hat sich bei allen unseren Experimenten herausgestellt.

Man kann also die Ergebnisse dieser Versuche in der Weise verallgemeinern, dass basale Stammstücke von Pennaria mehr Fähigkeit haben, regenerativ Stammverlängerungen zu bilden, und dass diese Fähigkeit apicalwärts abnimmt. Dagegen haben die apicalen Theile von PennariagröBeres Bestreben, an den Seitenästen Hydranten zu regeneriren und neu zu bilden. Diese Fähigkeit nimmt basalwärts in den einzelnen Regionen des Stocks ab.

Nun müssen wir noch darauf aufmerksam machen, dass die apicalen Theile bei Pennaria, abgesehen vom terminalen Hydranten, genetisch jünger sind, als die basalen, was auch vielleicht nicht ohne Einfluss auf den Verlauf der formativen Processe ist.

Nicht nur die Regenerationserseheinungen, sondern auch alle bei den großen Stämmen beschriebenen-Regulationseinrichtungen kann man bei diesen einzelnen Stammstiucken beobachten. Auch bei ganz kleinen Stammstücken, die nur einen Seitenast besitzen, sind außer der Regeneration der Hydranten auch die Zellverlagerungserscheinungen und das spontane Abtrennen der leeren Perisarkröhrchen wahrzunehmen. Die Textfig. 13-18 mögen den Regenerationsverlauf an einem kurzen Stammstück mit einem Seitenaste veranschaulichen. Nach dem Abschneiden der sieben Hydranten an dem Seitenast (Textfigur 13) bildet sich an den beiden Stammenden je ein neuer Hydrant 
und ebenso an dem Seitenast, am distalen Fnde beginnend, eine Anzahl Hydranten (Textfig. 14). Das Stiick, welches vor der Opcration sicben Hydranten besaß, hat jetzt (Textfig. 14) zwei Stammhydranten und sechs

Fig. 13.

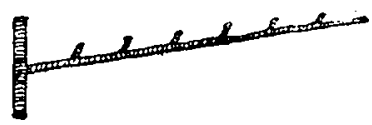

Fig. 15.

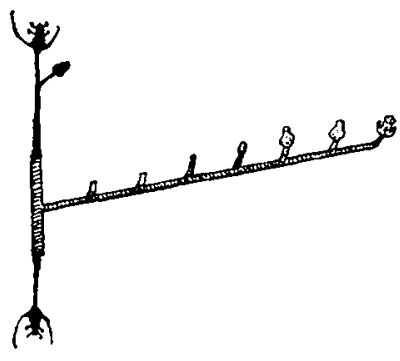

Fig. 17.

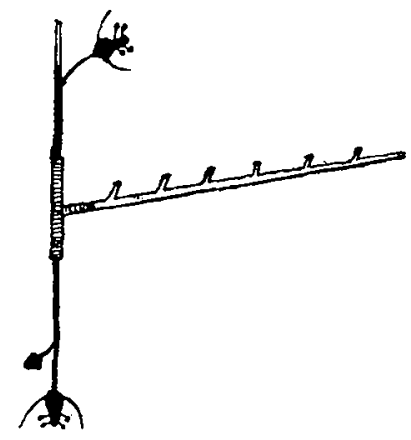

Fig. 14.

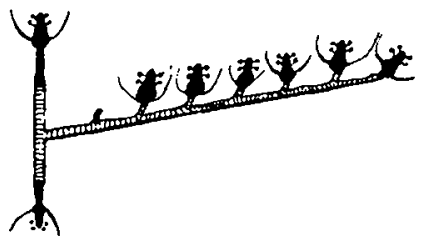

Fig. 16.

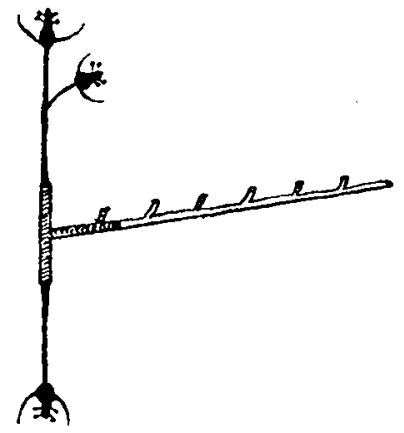

Fig. 18.

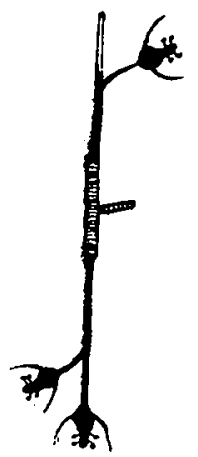

Regenerationsverlauf an cinem Stammstück mit einem Seitenast.

Hydranten am Seitenast. Dann nach der typisch verlaufenden Degeneration (Textfig. 15 zieht sich das Cönosark vom Seitenast zurück (Textfig. 16), wäbrend sich gleichzeitig wahrscheinlich auf Kosten dieses aus dem Seitenast zuriickgervanderten Zellınaterials ein neuer 
Hydrant seitlich (Textfig. 16) an dem apical nengebildeten Stamm bildet. Später degenerirt der Hydrant am apicalen Stammende, das Cönosark zieht sich etwas zurück und gleichzeitig entwickelt sich ein neuer Seitenhydrant (Textfig. 17) an dem basal neugebildeten Stamm. Während der Entwickelung dieses Hydranten fällt das leere Perisarkröhrchen des Seitenastes ab. In anderen Fällen wird, wenn die Neubildung der Seitenhydranten an den Stammverlängerungen unterbleibt, am Seitenast an der Stelle, wo das leere Perisarkröhrchen abgetrennt wurde, ein neuer Hydrant gebildet.

Aus dem Verlauf dieses Experiments ergiebt sich, dass bei begrenzter Menge des bildenden Materials die Bildung eines neuen Hydranten durch die Degeneration eines anderen, resp. durch Heranziehen des Cönosarks von anderer Stelle her ermöglicht wird.

\section{Regulationserscheinungen an kleinen Stammstiicken ohne Seitenäste.}

Um die Regenerationsfähigkeit kleiner Stammsticke festzustellen, wurden von Stämmen die Seitenäste dicht am Stamm abgeschnitten und dann die Stämme in kleine Stücke von $1-7 \mathrm{~mm}$ zerlegt. Die einzelnen Stücke wurden der GröBe nach sortirt, in verschiedene Glasschalen gebracht und dort beobachtet. $1 \mathrm{~mm}$ lange Stïcke haben nie Hydranten, sondern stets sehr kurze Stolonen gebildet; bei $2 \mathrm{~mm}$ langen Stïcken gelang es einige Male, Hydranten zu erhalten (von 20 Stïcken etwa 2); von $3 \mathrm{~mm}$ aufwärts nimmt die Häufigkeit der Hydrantenbildung zu, so dass bei Stücken von 6 und $7 \mathrm{~mm}$ an mehr als der Hälfte aller Stïcke ein Hydrant entsteht. Die Hydrantenbildung hängt also von der Länge des betreffenden Stiicks, d. h. von der Menge des zur Verfügnng stehenden Cönosarkmaterials ab. Als Beweis für diese Abhängigkeit mag noch folgender Versuch dienen. Wie oben hervorgehoben wurde, bilden die $2 \mathrm{~mm}$ langen Stämme in den meisten Fällen gar keine Polypen, oder doch nur äußerst selten. Legt man 5-10 Stücke zu $2 \mathrm{~mm}$ Länge in einer Reihe so dicht an einander, dass das aus den einzelnen Stücken hervorwachsende Cönosark sich berührt, so verwachsen dadurch die einzelnen kleinen Stïcke. Derartige aus mehreren kJeinen zusammengewachsenen Stücken bestehende Stämmchen bilden in allen Fällen wenigstens an einem Ende einen Hydranten, meist an beiden Enden. Der Versuch lässt sich noch in der Weise anstellen, dass die 
einzelnen Stücke so liegen wie nebenstehende Fig. 19 angiebt. So ergeben sich für die sechs $2 \mathrm{~mm}$ langen Stücke drei freie Wundflächen (die übrigen verschmelzen mit einander), und es gelingt, wenn auch nicht immer, von diesen sechs Stücken drei Hydranten regenerativ zu erhalten. Dadurch, dass die an einander stoßenden Wunden durch das sich verbindende und Perisark ansscheidende Cönosark verkittet werden, steht für die freien Wundflächen zur Hydrantenbildung mehr Material zur Verfuigung: kleine Stiucke mit einander verbunden zeigen dasselbe Verhalten, wie ein entsprechend großes ganzes Stück: sie bilden Hydranten. Wir haben in Vorhergehenden darauf hingewiesen, dass an kleinen Stücken durch Regeneration gewöhnlich nur Stolonen entstehen. Die Wachsthumsgeschwindigkeit dieser Stolonen ist auch von der Länge des betreffenden Stücks in gewissem Maße abhängig. Textfig. 20 und 21 stellen zwei Stammstücke ron 6 und $2 \mathrm{~mm}$ Länge dar, die zu glei-

Fig. 19.

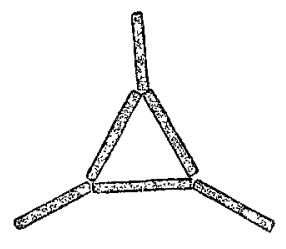
cher Zeit abgeschnitten und 24 Stunden danach gezeichnet wurden. An dem längeren Stück (Textfig. 20) ist durch den Neubildungsprocess in derselben Zeit bedeutend mehr geleistet worden als an dem kürzeren Stück (Textfig. 21).

Legt man kleine Stïcke in geringer Entfernung von einander so hin, dass die von den einzelnen Stücken auswachsenden Stolonen sich treffen können, so sind dadurch die Bedingungen geschaffen, unter denen ein Verwachsen von Stolonen verschiedener Stücke begünstigt wird. Es ist uns aus früheren Bemerkungen bekannt, dass bei Pennaria auswachsendes Cönosark immer mit neuem Perisark umgeben ist. Wenn nun zwei Stolonenenden verschiedener Stücke auf einander treffen, dann findet die uns schon bekannte (vgl. pag. 97) Eigenschaft der ektodermalen Zellen, Perisark in bestimmten Fällen zu lösen, Verwendung: an den Punkten, wo zwei answachsende Stolonen (sei es von demselben Stück oder von fremden Stücken) auf einander treffen, werden die beiden trennenden Perisarkmembranen aufgelöst und dadurch die Herstellung der Kontinuität des Cönosarks von mehreren Stuicken ermöglicht. Die vereinigten Stücke verhalten sich wie ein Organismus und es sind desshalb an ihnen auch die Wanderungs-, resp. Verlagerungsprocesse des Cönosarks, innerhalb des Perisarks zu beobachten. Dabei verlässt das Cönosark nicht selten vollkommen einen Theil der früher neugebildeten Perisarkröhrchen und verlagert sich in andere Theile des gemeinsamen Organismus. 


\section{Regenerationserscheinungen an Hauptstämmen nach Abschneiden aller Seitenäste.}

Nach Abschneiden aller Seitenäste mit ihren Hydranten vom Hauptstamm treten die Regenerationserscheinungen in ähnlicher Weise auf, wie wir das früber beschrieben haben. Die Regeneration beginnt also an dem apicalen Ende, an dem sich der erste Hydrant entwickelt und schreitet basalwärts vor; nach und nach erscheinen an der Stelle der abgeschnittenen Seitenäste neue Hydranten, ebenso am basalen Ende. Die Stiele der Hydranten wachsen in die Länge, erreichen aber nie die ursprïngliche Länge der abgeschnittenen Seitenäste, abgesehen etwa von dem ersten und zweiten apicalen Seitenast. Die Leistung der Regenerationsthätigkeit ist hier bedeutend schwächer, als bei einem Stamm, dem die Seitenäste gelassen und nur die Polypen abgeschnitten wurden. Nehmen wir einen Stamm mit 12 Seitenästen, die 85 Hydranten tragen, und schneiden nur die letzteren $a b$, so ist dieser operirte Thierstock im günstigen Falle im Stande, 85 Hydranten regenerativ zu erzengen. Würde man indessen demselben Stamm auch die 12 Seitenäste abschneiden, so würdè er

Fig. 20.

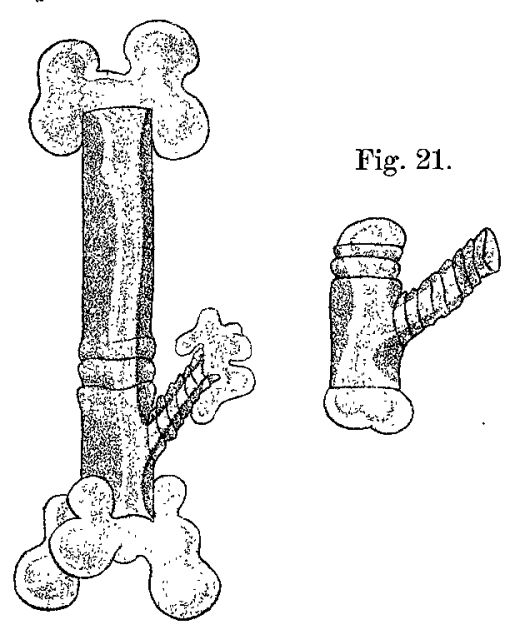
im günstigen Falle 14 (den apicalen und basalen Stammhydranten mitgerechnet) Hydranten bilden. Sehr oft regeneriren indessen an den basalen Astwunden keine Hydranten. Dies kann in gewisser Weise dadurch ansgeglichen werden, dass einige von den apicalen neuen Hydranten kräftigeres Stielwachsthum zeigen und einen oder zwei (tertiäre) Seitenhydranten bilden. In keinem Fall konnten wir jedoch auch bei Mitrechnung dieser tertiären Polypen feststellen, dass die Zahl der hier producirten Hydranten größer wäre, als die Zahl der abgeschnittenen Äste plus den beiden Endhydranten. In den Fällen, wo die Bedingungen dazu gegeben waren (Berührung mit festem Boden), haben sich regenerativ oder heteromorphisch Stolonen entwickelt, mit denen sich das Thier an dem Boden festklebte. Als seltene Ausnahmen müssen die Fälle betrachtet werden, wo sich Stolonen an 
Wundflächen bilden, obschon die Wundfläche frei vom Wasser umspült wird.

Entfernt man von 1-2 em langen Stammstücken an kleinen Stellen das Perisark, so beginnt das dort bloßgelegte und bei dem Ausschneiden des Perisarks wohl stets etwas verletzte Cönosark wulstige Wucherungen zu bilden. Je nach der Größe des ausgeschnittenen Perisarkstückchens bilden sich eine größere oder geringere Anzahl von höckerartigen Vorwölbungen, die zu kurzen Stolonen auswachsen. Diese Stolonen verzweigen sich trotz ihrer Kürze, ihre einzelnen Äste vereinigen sich in der oben beschriebenen Weise mit einander, und so bildet sich in kurzer Zeit ein die Umgebung der Wundfläche überziehendes Stolonengeflecht. Selten kommt es vor, dass ein Stolo sich etwas von der Unterlage erhebt, nie wurde aber bei diesen Versuchen Hydrantenbildung beobachtet.

\section{Regulationserscheinungen an isolirten Seitenästen.}

Die einzelnen Seitenäste wurden vom Stamm abgeschnitten und von ihnen ihre Hydranten. Die Äste wurden in Gefäßen aufgehängt oder auf den Boden hingelegt. Im ersteren Falle bildeten sich an allen Wundstellen, wo überhaupt regenerative Bildungen sich zeigten, nur Hydranten. Meist wurden indessen die proximalen Hydranten

Fig. 22.

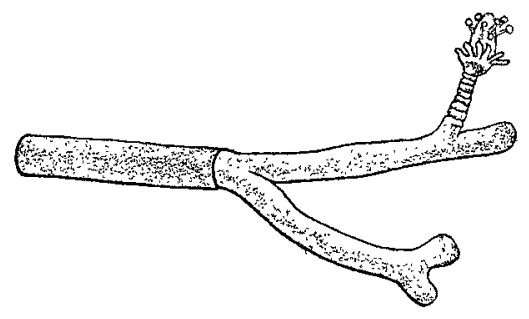
nicht regenerirt, sondern nur die distalen und an der $\mathrm{Ab}$ trennungsstelle vom Stamm ein Hydrant. Der Kopf des letzteren und ebenso der des distalen Endhydranten ist stets etwas nach der Seite gebogen, auf der am Seitenast die übrigen Hydranten stehen. Wenn sich an dem Stiel des proximalen Endhydranten eine Hydrantenknospe bildet, so ist sie stets ebenfalls nach dieser Seite gerichtet. In einem Falle wurde auf der entgegengesetzten Seite eine Stolonenbildung beobachtet. Wurden die Seitenäste auf den Boden so hingelegt, dass das ans dem proximalen Ende hervorwachsende Cönosark den Boden berührt, so bildet sich stets ein Stolo. In einer Versuchsreihe erhielten wir durchgehend folgendes Resultat: Während am distalen Astende und an den nächsten Hydrantenstielen Hydranten regenerirten, bildete sich am proximalen Ende ein Stolo, der sich 
bald gabelte. Die neu gebildeten Hydranten degenerirten und das Cönosark zog sich etwa bis zur Mitte des Astes zurück. Der Stolo wuchs in die Länge und anf der Oberseite des einen Stolonenastes bilảete sich eine Knospe, die sich zum Hydranten (Textfig. 22) und durch kräftiges Stielwachsthum zu beträchtlicher Höhe entwickelte. Auch hier geht also einer Hydrantenregeneration Cönosarkriickzug oder Degeneration eines anderen Hydranten vorauf. Der Theil des Perisarks, aus welchem sich Cönosark zurïckgezogen hat, wurde abgetrennt und an der Abtrennungsstelle wurde in einzelnen Fällen ein neuer Hydrant gebildet.

\section{Ist die Regeneration der Hydranten bei Pennaria vom Licht abhängig?}

Von Miss Peebles wird angegeben, dass das Licht auf die Regeneration bei Pennaria einen günstigen Einfluss ansübe und dass bei Ausschluss des Lichtes die Zahl der gebildeten Hydranten kleiner sei als bei Thieren, die im Licht regenerirten. "The production of new hydranths on the cut end of Pennaria takes place slowly in the light; there was no perceptible change in the rate when the pieces were objected to darkness but the percentage of hydranths formed, was not so large as in the light. « Um diese Frage zu prüfen, haben wir einige Experimente so angestellt, dass eine Anzahl von Stämmen mit ihren Seitenästen nach Abschneiden der gesammten Hydranten in großen Gefäßen aufgehängt wurden und das Gefäß mit eìnem schwarzen Kasten bedeckt wurde, so dass der Zutritt des Lichtes vollkommen ausgeschlossen war. Die Zahl der abgeschnittenen Polypen wurde in allen Fällen notirt. Von derselben Pennariakolonie wurde ein ähnlicher Stamm auf dieselbe Weise operirt und zur Kontrolle in einem beleuchteten Bassin aufgehängt.

Das Ergebnis einer Anzahl Versuche giebt die nachfolgende Tabelle, die sich nur auf das Regenerationsergebnis der im Dunkeln gehaltenen Stämme bezieht:

\begin{tabular}{c|c|c}
\hline $\begin{array}{c}\text { Zahl der } \\
\text { abgeschnittenen } \\
\text { Hydranten }\end{array}$ & $\begin{array}{c}\text { Zahl der } \\
\text { regenerirten } \\
\text { Hydranten }\end{array}$ & $\begin{array}{c}\text { Das VerhäItnis aer Zahl der regene- } \\
\text { rirten Hydranten zu der abgeschnit- } \\
\text { tenen in Procenten ausgedräckt }\end{array}$ \\
\hline 95 & 69 & 72 \\
95 & 88 & 92 \\
57 & 50 & 88 \\
112 & 58 & 52
\end{tabular}


Das Mittel der angeführten Procentzahl der regenerirten Hydran. ten beträgt hier $77 \%$. Das Mittel der in der gleichen Zeit im Licht regenerirten Hydranten beträgt aber 67\% (vgl. Tabelle anf pag. 85). Daraus geht hervor, dass die Regeneration im Dunkeln durch den Lichtmangel nicht ungïnstig beeinflusst wurde.

\section{Resultate der Experimente.}

Die Regeneration der Hydranten an ganzen Stämmen beginnt am apicalen Ende des Stammes und schreitet basalwärts vor, an den Seitenästen beginnt sie am distalen Ende und schreitet proximalwärts vor; im Mittel regeneriren $67 \%$ der abgeschnittenen Hydranten. Bei der Regeneration der Hydranten spielen die karyokinetischen Processe keine oder wenigstens ganz unbedeutende Rolle. Die Hydrantenentwickelung ist als Transformationsprocess aufzufassen, wobei die hierher verlagerten Cönosarkzellen direkt zu Bestandtheilen der sich bildenden Hydranten werden. Die regenerirten Polypen unterliegen nach küuzerer oder längerer Zeit (24-48 Stunden) der Rückbildung. Diese Degeneration verfolgt den entgegengesetzten Weg, wie die Regeneration. Sie verläuft basal-apicalwärts, an den einzelnen Seitenästen proximal-distalwärts. Diese Degenerationserscheinungen beruhen bauptsächlich auf Zerfall der Zellelemente, wobei wahrscheinlich der größere Theil der Zerfallsprodukte durch Körnchenströmung in das Stammlumen übergeht und dort von den Entodermzellen resorbirt wird. Die Degeneration der Hydranten ist jedenfalls nicht als direkte Transformation der Hydrantenzellen in Bestandtheile des Thierstammes aufzufassen.

Nach dem Abfall der Polypen zieht sich das Cönosark ron den distalen Theilen der Seitenäste zurück. Das Zurückziehen des Cönosarks muss als regulativer Process aufgefasst werden, das Material wird dadureh verlagert. Die Verlagerungsprocesse (vgl. LOEb, 1903) finden immer statt, wenn formative Processe an einem anderen Punkte des Organismus vor sich gehen sollen. Der Mechanismus der Verlagerung beruht auf den aktiven Kontraktionen des Cönosarkstammes mit gleichzeitiger Umordnung der Zellelemente. Der Verlagerung muss eine Lockerung des Zusammenhangs des Cöno- und Perisarks vorausgehen.

Das aus einem Seitenaste sich zurückziehende Cönosark macht 
an irgend einer Stelle des Seitenastes Halt und trennt dort die leere von ihm verlassene Perisarkröhre ab. Dieses Abtrennen der leeren Perisarkröhren findet in der Weise statt, dass sich die Spitze des innerhalb des Perisarkrohres zurückwandernden Cönosarkstammes wieder verdickt, bis ringsum der Kontakt mit dem Perisark wieder gewonnen ist. An dieser ringförmigen Kontaktstelle gruppiren sich Ektodermzellen in bestimmter Weise, scheiden ein Perisark lösendes Sekret aus, wodurch die Bildung einer rings um das Perisark verlaufenden Rinne an der inneren Perisarkfläche veranlasst wird. Da diese Rinne bis zur Oberfläche des Perisarks vordringt, bricht der leere distale Abschnitt des Perisarkrohres ab. Nach diesem sspontanen Abtrennen « des leeren Perisarkrohrabschnittes findet entweder an der Bruchstelle Hydrantenregeneration statt, oder das Cönosark zieht sich weiter stammwärts zurück, um an einem anderen Punkte das Abtrennen des wieder verlassenen Abschnittes des Perisarkrohres zu wiederholen.

Das spontane Abtrennen der leeren Perisarkröhrchen ist also eine Regulationseinrichtung, welche für weitere Regenerationsthätigkeit des Thieres sich vortheilhaft erweist. Obschon das Bildungsmaterial durch vorhergehende Regenerationsprocesse theilweise erschöpt worden ist, ist eine weitere Regenerationsleistung doch möglich, da jetzt die Thierdimensionen verkleinert sind (durch das.Abtrennen der leeren Perisarkröhren), und nun die Menge des vorhandenen Zellmaterials für regenerative Processe gen ü gt.

Der Mechanismus des Abtrennens der leeren Perisarkröhrchen lehrt, dass dieselben Ektodermzellen, welchedas Perisark auscheiden, unter gewissen Bedingungen die entgegengesetzte Thätigkeit, nämlich Perisark zu lösen, leisten können. Die Eigenschaft der Ektodermzellen, unter bestimmten Bedingungen Perisark lösend zu wirken, findet auch Verwendung bei der Verwachsung von Stolonen verschiedener Stücke.

Bei den regenerativen, wie auch heteromorphotischen Processen treten bei Pennaria die Polaritätserscheinungen sehr deutlich hervor. Sie äuBern sich in dem Neigungswinkel der neuentstandenen Seitenäste. Bildet sich am apicalen Stammende regenerativ eine Stammverlängerung, so liegen die sich daran bildenden Seitenhydranten resp. Äste in derselben Ebene, wie die alten Seitenäste und bilden denselben Winkel mit 
dem Stamm. Bildet sich am basalen Stammende heteromorphisch ein Hydrant und gehen von diesem auch neue Seitenhydranten resp. Äste aus, so liegen sie zwar ebenfalls in der Ebene der alten Seitenäste, haben aber umgekehrte Richtung, wie die alten: der spitze Neigungswinkel ist dem basalen Endhydranten zugewendet. Stämme mit abgeschnittenen Seitenästen regeneriren an allen Wundstellen Hydranten mit ihren Stielen, niemals die ganzen abgeschnittenen Äste. Die Regenerationsfähigkeit des Pennariastammes äußert sich verschieden, je nachdem ein apicales oder ein basales Stück beobachtet wird: Die basalen Stammstïcke haben mehr Fähigkeit Stammverlängerungen regenerativ zu bilden und diese Fähigkeit nimmt apicalwärts ab. Dagegen haben die apicalen Theile von Pennaria größeres Bestreben, an den Seitenästen Hydranten zu regeneriren. Diese Fähigkeit nimmt wiederum basalwärts in den einzelnen Regionen des Stocks ab. Lichtmangel hat keinen ungünstigen Einfluss auf die Regenerationsthätigkeit ganzer Stämme.

\section{Nachtrag.}

Nach Einsendung unserer Arbeit zum Druck ist eine Abhandlung von Paul Cerfontaine erschienen: Recherches expérimentales sur la Régénération et l'Hétéromorphose chez Astroïdes Calycularis et Pennaria Cavolinii (Arch. Biol. T. XIX. 1902). Da unsere Versuche über Pennaria fortgesetzt werden sollen, sobald das Material wieder für Experimente geeignet sein wird, so wird sich später Gelegenheit bieten, auf die Arbeit von CERFontaINe näher einzugehen.

\section{Litteraturverzeichnis.}

Driesch, H., Analytische Theorie der organischen Entwickelung. Leipzig 1894. - Studien über das Regulationsvermögen der Organismen. I. Von den regulativen Wachsthums- und Differenzirungsfähigkeiten der Tubularia. Archiv f. Entwickelungsmech. Bd. V. 1897.

— Strdien über das Regulationsvermögen der Organismen. II. Quantitative Regulationen bei Reparation der Tubularia. Arehiv f. Entwickelungsmech. Bd. IX. 1899.

- Die organischen Regulationen. Leipzig 1901.

FredericQ, L., L'autotomie on la mutilation dans le regne animal. Bull. de l'Acad. roy. de Belgique. XXVI. 1893.

GIARD, A., L'autotomie dans la série animale. Revue scientifique. 1887. pag.629. GoDLEWSkI, E., jun., 0 regeneracyi tubularyj. Rozpr. Akad. Umiejętności w Krakowie. Dasselbe englisch: Regeneration in Tubularia after longitudinal splitting. Preliminary communication. Bull. de l'Académie des Sciences de Cracovie. Juillet 1902. 
Herbst, C., Formative Reize in der thierischen Ontogenese. Leipzig 1901.

LOEB, J., Untersuchungen zur physiologischen Morphologie der Thiere. I. Über Heteromorphose. Würzburg 1891.

- Untersuchungen zur physiologischen Morphologie der Thiere. II. Organbildung und Wachsthum. Würzburg 1892.

— On Some Facts and Principles of Physiological Morphology. Biol. Lect. Woods Holl in 1893, 1894.

- On the Transformation and Regeneration of Organs. Americ. Journ. of Physiol. IV. 1900.

Morgan, T. H, Regeneration. New York-London 1901.

Peebles, Fu., Experiments in Regeneration and in Grafting of Hydrozoa. Archiv f. Entwickelungsmech. Bd. X. 1900.

- Further Experiments in Regeneration and Grafting in Hydroids. Archiv f. Entwickelungsmech. 1902.

Przibram, H., Experimentelle Studien über Regeneration. II. Mittheilung. Archiv f. Entwickelungsmech. Bd. XIII. 1902.

Roux, W., Beiträge zur Entwickelungsmechanik des Embryo. VII. Über Mosaikarbeit und neuere Entwickelungshypothesen. Anatom. Hefte. 1893.

-_- Gesammelte Abhandlungen. Bd. II. 1895.

Stevens, N. M., Regeneration in Tubularia. Archiv f. Entwickelungsmech. Bd. XIII. 1901.

STrasser, H., Regeneration und Entwickelung. Rektoratsrede. Jena 1899.

\section{Erklärung der Abbildungen,}

\section{Tafel II.}

Fig. 1 $a-f$ stellt schematisch in Längsschnitten den Wundverschluss nach Durchschneidung des Stammes dar. $a$ unmittelbar, $b 5$ Minuten, $c 10$ Minuten, $d 15$ Minuten, $e 30$ Minuten, $f 6$ Stunden nach der Operation. Vergr. 10 fach.

Fig. 2-4. Regenerationsstadien von Hydranten. Vergr. etwa 20 fach.

Fig. 5. Längsschnitt durch das Ende eines wachsenden Stolos. Färbung Hämalaun-Eosin. Vergr. 64 fach.

Fig. 6-8. Längsschnitte durch drei auf einander folgende Regenerationsstadien von Hydranten. Färbung Hämalaun-Eosin. Vergr. $64 \mathrm{fäch}$.

Fig. 9. Stück eines Stammes mit einem Seitenaste. Das Cönosark befindet sich im Rückzuge. Vergr. 20 fach.

\section{Tafel III.}

Fig. 1. Längsschnitt durch einen Ast, in dem das Cönosark im Begriff ist, das verlassene Stück der Perisarkröhre abzutrennen. Färbung Hämalaun-Eosin. Vergr. 150 fach.

Fig. 2-6. Der Vorgang des Abtrennens leerer Perisarkröhren in fünf Stadien nach dem lebenden Objekt gezeichnet. Vergr. 15 fach.

Fig. 7-12. Sechs auf einander folgende Degenerationsstadien von Hydranten nach dem lebenden Objekt gezeichnet. Vergr. 10 fach.

Fig. 13-17. Längsschnitte durch Degenerationsstadien von Hydranten: 13 und 14 Eisenalaun-Hämatoxylin, 15-17 Hämalaun-Eosin. Fig. 13 entspricht einem Medianschnitt durch das in Fig. 7 abgebildete Stadium, Fig. $14=$ Fig. 8 , Fig. $15=$ Fig. 9, Fig. $16=$ Fig. 10 , Fig. $17=$ Fig. 11. Vergr. 40 fach. 
116 R. Gast und E. Godlewski jun., Die Regulationserscheinungen etc.

Die bei der Figurenbezeichnung auf Taf. II and III gebrauchten Abkürzungen bedeuten:

\begin{tabular}{|c|c|c|c|}
\hline v.Per & altes Perisark, & $K . R$ & Kernreste, \\
\hline Bas. $M$ & Basalmembran. & Kn.Tent & Knopftentakel \\
\hline Bas.Tent & Basaltentakel, & $M$ & Mund, \\
\hline$C$ & Cönosark, & $N_{x}$ & Nesselzellen, \\
\hline C.Z & Cönosarkzipfel, & n.Per & nenes Perisark, \\
\hline$D r . G r$ & $\begin{array}{l}\text { Gruppe von Zellen, welche } \\
\text { zeitweise wie Drüsenzellen } \\
\text { funktioniren, }\end{array}$ & $\begin{array}{l}\text { Per } \\
\text { Per.H } \\
\text { Per.Hö }\end{array}$ & $\begin{array}{l}\text { Perisark, } \\
\text { Perisarkhäutchen, } \\
\text { Perisarkhöhlung, }\end{array}$ \\
\hline Be & Ektodermzellen, & Per.R & leere Perisarkröhre, \\
\hline$E c \cdot B r$ & Ektodermbrïcken, & Per.R $R i_{1}$ & Perisarkrinne, \\
\hline$H . A$ & Hydrantenanlage, & Per.Ri $i_{2}$ & Perisarkriss, \\
\hline$H . R . K$ & enrestkörp & $S . A$ & Seitenast, \\
\hline$H . S t$ & Hydrantenstiel, & $S t$ & Stamm. \\
\hline
\end{tabular}

